\title{
Influence of morphological changes on suspended sediment dynamics in a macrotidal estuary: diachronic analysis in the Seine Estuary (France) from 1960 to 2010
}

\author{
Grasso Florent ${ }^{1,}{ }^{*}$, Le Hir Pierre ${ }^{1}$ \\ ${ }^{1}$ IFREMER, DYNECO DHYSED, Ctr Bretagne, CS 10070, F-29280 Plouzane, France. \\ * Corresponding author : Florent Grasso, email address : florent.grasso@ifremer.fr
}

\begin{abstract}
:
Estuaries are subject to extensive morphological changes through human activities, such as deepening and narrowing via dredging and channelization. The estuary sediment load, characterised by the estuarine turbidity maximum (ETM), can severely increase in response to channel deepening, shifting the estuary from a natural to hyperturbid state. The main processes driving the estuarine circulation, hydrology and sediment dynamics are relatively well known. However, their relative influence on suspended sediment concentration (SSC), as well as their role in the transition toward hyperturbid estuaries, is still a subject of debate. Therefore, this study aims at investigating the relative contribution of key estuarine drivers (gravitational circulation and tidal pumping mechanisms) on the ETM dynamics under significant estuary morphological changes. In a 3D numerical model of the Seine Estuary (France), three bathymetries from the last 50years (1960, 1975 and 2010) were implemented, characterising the gradual estuary deepening and narrowing. The morphological changes induce an expected tidal amplification in the main channel, associated with a decrease of the tidal duration asymmetry. The salinity front slightly migrates up-estuary and the stratification strengthens, resulting in a higher and upper-estuary SSC distribution. Starting from a dominantly natural system driven by the tidal pumping mechanism in 1960, the contribution of the gravitational circulation strongly increased in the present-day anthropogenically-controlled system. Contrastingly, the maximum ETM mass barely changes with the morphological changes and dredging activities have hardly any influence. Hence, the maximum ETM mass in the Seine Estuary would principally result from the tidal forcing rather than the morphology.
\end{abstract}

Keywords: Estuary deepening and narrowing, Sediment dynamics, Turbidity maximum, Tidal asymmetry, Stratification, Numerical modelling, Morphological changes 


\section{Introduction}

Estuaries constitute dynamic areas mixing fresh riverine water within sea water, providing high levels of nutrients both in the water column and in the sediment that makes estuaries among the most productive natural habitats in the world (Morris et al. 1978). Nevertheless, these highly anthropized ecosystems are drastically vulnerable to human pressures (Nichols et al. 1986). Representing strong economic stakes, estuaries undergo considerable changes through engineering works, such as dredging activities, dike construction and harbour extensions, potentially associated with channel deepening and estuary narrowing (e.g. Avoine et al. 1981).

Many estuaries around the world are characterized by an estuarine turbidity maximum (ETM), defining a zone of high suspended sediment concentration (SSC) that can reach tens to hundreds of g/l (e.g. Glangeaud 1938; Le Hir and Thouvenin 1994; Sottolichio et al. 2000; Uncles 2002; Sommerfield and Wong 2011; Bi and Toorman 2015; Jalón-Rojas et al. 2016; Grasso et al. 2018). Winterwerp (2011) summarized the various mechanisms classically attributed to the transport and trapping of fines in estuaries and tidal rivers and the formation of an ETM in relation to the physical properties of the sediment. These mechanisms are defined as: tidal asymmetry in ebb/flood current velocities (e.g. Allen et al. 1980); tidal asymmetry in sediment mixing (e.g. Geyer 1993; Jay and Musiak 1994); gravitational circulation due to salinity gradients (e.g. Dyer 1973); scour and settling lag effects (Postma 1961); sediment availability (e.g. Dickhudt et al. 2009); asymmetry on mud floc settling velocities (e.g. Scully and Friedrichs 2007); and topographical effects, such as convergence or divergence of channel cross sections (Friedrichs et al. 1998). Various methods have been proposed to investigate the relative contribution of the physical processes to the ETM formation and dynamics, such as the decomposition of tidal currents (Burchard et al. 2018) and the process-based numerical modelling with inclusion/exclusion of specific mechanisms (Brenon and Le Hir 1999). Recently, Grasso et al. (2018) proposed a different approach to analyse the sensitivity of ETM and salinity front locations to tidal forcing. Based on along-estuary location signals that are detrended from the river flow variability, this method emphasizes the contribution of (i) gravitational circulation mechanism, favoured by stratification more pronounced during neap tides, and (ii) tidal pumping mechanism, induced by tidal asymmetry more pronounced during spring tides. In addition, it highlights the hysteresis between neap and spring phasing, associated with the delay for tidal pumping and stratification to fully develop.

Burchard et al. (2018) recently provided a review on sediment trapping mechanisms in estuaries. They raised a number of research challenges that remain ill-known, such as the influence of morphological changes (e.g. deepening or narrowing) on estuarine sediment dynamics and the transition from normal to hyperturbid estuaries. Such a topic has been of interest for many years, but the discussions are not conclusive yet. Investigating the influence of estuary narrowing on tidal dynamics, Lanzoni and Seminara (1998) observed that when channel convergence is strong or moderate, weakly dissipative estuaries turn out to be ebb dominated. However in strongly dissipative estuaries, tide propagation becomes a strongly nonlinear phenomenon that invariably leads to flood dominance.

Most of the studies investigating the influence of geometrical/bathymetrical changes on estuarine turbidity levels and dynamics refer to channel deepening. For instance, Winterwerp (2011) inferred that in response to deepening of the Ems River, the increase of the river sediment load, shifting the system from a normal to hyperconcentrated state, followed three phases: (i) firstly through an increase in the up-river transport by gravitational circulation (Talke et al. 2009) and a decrease in river-induced flushing; (ii) secondly through an increase of internal 
tidal asymmetry because of pronounced interactions between the sediment load and the turbulence vertical mixing; and (iii) finally through the formation of thick fluid mud layers with up-river sediment transport dominated by tidal asymmetry of the current velocity. Such an increase of sediment load resulting in the transition from normal to hyperturbid estuaries has been observed in other estuaries, as for instance in the Loire Estuary (France) (Winterwerp et al. 2013). Nonetheless, Winterwerp et al. (2013) inferred from an analytical model that the observed amplification of the tide in four rivers could not be explained from geometrical/bathymetrical changes in these rivers alone. Particularly, the hydraulic drag reduction due to the fine sediment load increase played an important role as well. However, the authors pointed out that more advance models, accounting for nonlinear effects and detailed bathymetrical features, are required to analyse effects of tidal reflections and river flow in further detail.

Based on an exploratory, semi-analytical model, de Jonge et al. (2014) investigated the influence of channel deepening on estuarine turbidity dynamics. In agreement with Winterwerp et al. (2013), they urged to use all available methods, including state-of-the-art simulation models, when exploring the effects of human intervention in natural systems. Like-minded, van Maren et al. (2015) implemented a numerical model on the Ems Estuary, which experienced a strong increase of SSC following its deepening through the last decades. The aim was to understand the relative role of bed roughness and bed topography on sediment import mechanisms and sediment concentration. They applied the same forcing on four bathymetries from 1945 to 2005 and changed the bed roughness to calibrate the present and historic model scenario hydrodynamics. The estuary deepening led to a more pronounced flood-dominated tidal asymmetry (Chernetsky et al. 2010) and density-driven flow (Talke et al. 2009; Donker and de Swart 2013). It resulted in strengthening sediment import mechanisms related to resuspension, vertical mixing and flocculation, as described previously (Winterwerp 2011). Despite the channel deepening and the consequent tidal amplification, van Maren et al. (2015) observed little changes in tidal current and duration asymmetries. Nevertheless, the increasing tidal amplitude in the last decades enhanced the difference between the total sediment flux transported during flood and ebb flows, resulting in a larger up-estuary tidal transport. The study revealed that the sediment-induced density currents were not responsible for the high SSC. In addition, the vertical mixing asymmetry limitedly influenced the modelled up-estuary transport. In agreement with Winterwerp and Wang (2013), the authors concluded that the SSC increase in the last decades resulted from a decrease in river flushing in addition to an increase in tide-induced up-estuary transport. Both geometrical changes (i.e. channel deepening) and bed roughness changes (i.e. hydraulic drag reduction) were responsible of such dynamics.

The reduced river's flushing capacity and the enhanced flood flow dominance may lead to the creation of a second ETM related to the tidal pumping mechanism, located upstream of the formal ETM close to the salt wedge location (Winterwerp and Wang 2013). Nevertheless, with sufficient intertidal areas - i.e. at least 50\% of the width of the flow carrying cross-section - tidal conditions would remain ebb-dominant, preventing the formation of second ETM conditions. In addition, intertidal areas can accommodate large amounts of fine sediments, preventing their accumulation in the water column.

In line with the approach adopted by van Maren et al. (2015), this study is based on state-of-the-art simulations of the macrotidal Seine Estuary (NW France). A 3D numerical model, validated in hydrodynamics, hydrology and sediment dynamics against present-day observations (Grasso et al. 2018; Schulz et al. 2018), was implemented on three historic bathymetries (1960, 1975 and 2010) forced with the same realistic hydro- 
meteorological conditions of year 2010 (tide, wind, river flow, considered as representative of natural variability (Schulz et al. 2018)) and same bed roughness. Therefore, this semi-realistic diachronic analysis is carried out to investigate the influence of morphological changes on suspended sediment dynamics. These changes mainly consist in channel deepening and estuary narrowing, leading to an estuary divided between a main channel and secondary lateral channels. In addition, the method presented in Grasso et al. (2018) is used to compare the ETM dynamics in the different bathymetric configurations and to quantify the relative contribution of salinity gradient and tidal pumping mechanisms to estuarine dynamics.

\section{Historical development of the lower Seine Estuary}

\subsection{Study area}

The macrotidal Seine Estuary, located in the Northwestern part of France, is characterized by a semidiurnal tidal range (TR) varying from 3 to $8 \mathrm{~m}$ at Le Havre near the estuary mouth ('LH' in Fig. 1). It is one of the largest estuaries on the Northwestern European continental shelf, with a catchment area of more than $79,000 \mathrm{~km}^{2}$. The estuary stretches from the Bay of Seine open to the English Channel to the weir of Poses upstream, limit of the tidal influence. The Seine River flow $(Q)$ ranges from $100 \mathrm{~m}^{3} / \mathrm{s}$ to $2300 \mathrm{~m}^{3} / \mathrm{s}$ in low and high river flow periods, respectively, with a mean annual flow around $450 \mathrm{~m}^{3} / \mathrm{s}$ computed over the last 20 years. Accordingly, the mean Seine sediment supply reaches $725 \times 10^{6} \mathrm{~kg}$ per year (Landemaine 2016; Schulz et al. 2018).

The funnel-shaped estuary is exposed to western winds, so that the intertidal regions at the mouth are subject to erosion under the combined effect of waves and currents (Deloffre et al. 2007; Verney et al. 2007). The dominant wind direction is from southwest with average wind speeds of about $4 \mathrm{~m} / \mathrm{s}$ and peaks of more than $15 \mathrm{~m} / \mathrm{s}$. Waves enter the bay from northwest with typical significant wave heights of $0.5 \mathrm{~m}$ and peaks of more than $3.5 \mathrm{~m}$ in front of the estuary mouth. Schulz et al. (2018) provided a detailed description of wind and river flow forcing on the Seine Estuary over the last 20 years. The lower estuary is approximately extending from Caudebecen-Caux (along-estuary kilometric point 'kp' 310) to the "Engainement" at the mouth (kp 370) (Fig. 1 and Fig. 2). It is characterized by the presence of an ETM that has a pronounced control on the sedimentation patterns of subtidal areas and intertidal mudflats from the estuary mouth up to the upstream freshwater limit, which is few kilometres downstream of Caudebec-en-Caux (Avoine et al. 1981; Le Hir et al. 2001; Deloffre et al. 2005; Grasso et al. 2018).

\subsection{Historical development}

During the last two centuries, the Seine Estuary has been vastly altered by human activity (Avoine et al. 1981). As a result, the lower Seine River was changed from a dominantly natural system to an anthropogenically-controlled system. Recently, the present-day configuration (i.e. 2010) has been extensively analysed in terms of ETM dynamics, sediment fluxes and budgets (Grasso et al. 2018; Schulz et al. 2018).

In the last 50 years, i.e. from 1960 to 2010, extensive engineering works induced a deepening and narrowing of the lower estuary (Fig. 2). Starting from a poorly constrained system before 1960, a new main channel 
has been diked in the 70's (see blue lines in Fig. 1b) in order to enhance tidal ebb flows and to increase sediment flushing out of the estuary. It resulted in an estuary divided between a central ebb-dominated navigation channel and two secondary lateral flood-dominated channels. Then, a large extension of the Grand Port Maritime du Havre

(GPMH) between 1995 and 2005, named as "Port 2000", associated with the deepening and dredging of the channel leading to the Grand Port Maritime de Rouen (GPMR), shaped a deeper and narrower estuary configuration in 2010.

Consequently, intertidal areas in the lower estuary, here defined as the surfaces between the lowest water level (i.e. mean sea level $-4 \mathrm{~m}$ ) and the mean high-water level (i.e. mean sea level $+2 \mathrm{~m}$ ), decreased by $50 \%$ from the 1960-1975 configurations to the 2010 configuration $\left(30.6,31.3\right.$ and $20.4 \mathrm{~km}^{2}$ in 1960,1975 and 2010 , respectively). In 1960 and 1975, they represented approximately 19-20\% of the lower estuary area - computed as the sum of subtidal and intertidal areas - and only $14 \%$ in 2010.

\section{Numerical model setup}

A three-dimensional numerical model has been developed to study the hydro- and sediment dynamics of the Seine Estuary from the Bay of the Seine to the weir at Poses (Fig. 1a) with a particular interest on the lower estuary from the mouth to Tancarville (Fig. 1b), corresponding to the main area of the ETM excursion. Grasso et al. (2018) provided a detailed description of the numerical model setup and the validation of hydro- and sediment dynamics. The model skills, based on 1-year high-frequency measurements carried out at several locations, provide a satisfactory level of confidence to investigate the suspended sediment dynamics in a macrotidal estuary from tidal to annual time scales (e.g. Amoudry et al. 2014; Bi and Toorman 2015; van Maren et al. 2015; Toublanc et al. 2016). The main model characteristics are repeated in sections 3.1 and 3.2 .

\subsection{Hydrodynamic model}

A non-orthogonal curvilinear mesh was chosen to better respect the estuarine shape, to optimize the computation costs by lengthening the meshes in the direction of dominant tidal flows and to improve sediment flux estimates. Cells range from around $30 \times 100 \mathrm{~m}^{2}$ at the estuary mouth to $2 \times 2 \mathrm{~km}^{2}$ offshore and the bathymetries correspond to the years 1960, 1975 and 2010 (mean sea level chart datum).

The hydrodynamic model is based on the hydrostatic model MARS3D coupling barotropic and baroclinic modes (Lazure and Dumas 2008). The water column is discretized with 10 equidistant sigma layers and adaptive time steps range from 2 to $18 \mathrm{~s}$. Turbulence closure is based on a mixing length model that accounts for turbulence damping by density gradients (Cugier and Le Hir 2002). The circulation model is forced by the main tidal components at the sea boundary extracted from the CST France database (Service Hydrographique et Océanographique de la Marine, SHOM) and wind stresses and pressure gradients provided by the meteorological ARPEGE model (Meteo-France). The realistic Seine and Risle River flows are prescribed at Poses and at the Risle mouth (Fig. 1), respectively. In contrast to Grasso et al. (2018), waves are not simulated in this study. 
In order to solely analyse the influence of morphological changes on estuarine sediment dynamics, the bed roughness distribution is identical in the three configurations. It varies from the Bay of Seine to the upriver estuary to ensure the correct tide propagation along the estuary (Grasso et al. 2018).

\subsection{Sediment model}

The hydrodynamic model is coupled with the process-based sediment model for sand and mud mixtures MUSTANG (MUd Sand TrANsport modellinG) (Le Hir et al. 2011; Grasso et al. 2015; Mengual et al. 2017). The sediment bed is discretized with a maximum of 100 layers of variable thickness ranging from $1 \mu \mathrm{m}$ to $5 \mathrm{~mm}$. This multi-layer model accounts for the spatial and temporal variations of sand and mud content in the sediment, as well as for consolidation processes. In the water column, the model resolves advection/diffusion equations for different classes of particles. This study considers five classes of sediment representative of the Seine Estuary sediment modes (Lesourd et al. 2015): one gravel (diameter $d=5 \mathrm{~mm}$ ), three sands (coarse: $d=800 \mu \mathrm{m}$, fine: $d=210 \mu \mathrm{m}$ and very fine: $d=100 \mu \mathrm{m}$ ) and one mud. In the lower estuary, $40 \%$ of mud, $15 \%$ of very find sand, $30 \%$ of fine sand and $15 \%$ of coarse sand were initially distributed over a $3-\mathrm{m}$ thick bed. The mud advection is calculated by means of a complete $3 \mathrm{D}$ scheme with a variable settling velocity accounting for flocculation processes (Van Leussen 1994).

The erosion flux is based on Partheniades-Ariathurai's formulation (Partheniades 1965) and depends on the mass fraction of mud in order to distinguish cohesive and non-cohesive sediment behaviours. Consolidation is simulated by solving Gibson's equation for mixed sediments (Gibson et al. 1967), taking into account mud-sand segregation processes, permeability, and effective stress regimes of the sedimentation/consolidation phases (Grasso et al. 2015)

The Seine sediment supply is imposed at Poses at the same location as the river flow and is composed of the mud fraction. This mud flux varies with the Seine River flow, making a distinction between high river flow and low river flow. Such a method takes into account the sediment suspension hysteresis between pre- and postflood events. For further details as well as the calibration and validation of the model, please be referred to Grasso et al. (2018).

The maintenance of the GPMH and GPMR and of their access channels (Fig. 1b) requires extensive sediment dredging and dumping activities in the lower estuary (Marmin et al. 2014). Since these anthropogenic fluxes are 10 times larger than the ETM mass, dredging and dumping represent important processes to consider in simulating sediment dynamics in the Seine Estuary. The sediment model simulates these activities by removing the upper sediment layers in the dredged areas every $10 \mathrm{~min}$ if the sediment deposit exceeds a given elevation corresponding to the minimum water depth provided by the GPMH and GPMR. The dredged sediment mass is then released in the lowest cell of the water column in the associated dumping areas, i.e. Octeville for the GPMH and Kannik for the GPMR (Fig. 1b). It means that the dredged mass of sediment - including mud, sands and gravel - is expressed as a sediment concentration by dividing with the bottom water cell volume of the dumping location and then settles on its own to the bed. The dredging and dumping areas in the model correspond to the actual sites and only the 2010 configuration is associated with dredging activities. 
A morphostatic approach is adopted in this study (i.e. no morphodynamic coupling), which has been proved to be relevant for the analysis of suspended sediment dynamics at time scales of few years when morphological changes remain small relative to hydrodynamic processes. In addition, as waves are not simulated in this study, the contribution of waves on sediment resuspension is not taken into account. Therefore, the ETM mass can be underestimated during energetic storm events (Grasso et al. 2018). However, note that this work does not aim at providing the most realistic simulations, but rather to compare estuarine turbidity behaviours related to bathymetrical changes.

3.3 Model forcing and diachronic scenarios

The numerical model results presented in this study were obtained from simulations that ran during two years (from January 2009 to January 2011). The first year (2009) was defined as a spin-up period and the second year (2010) was used for the analyses. The year 2010 has been chosen for its hydrological conditions (mean annual flow of $\left.426 \mathrm{~m}^{3} / \mathrm{s}\right)$ representative of the last 20 years $\left(450 \mathrm{~m}^{3} / \mathrm{s}\right)$. In addition, it corresponds to the forcing period that Grasso et al. (2018) used to validate the model and that Schulz et al. (2018) analyzed in details.

The same 2010 realistic forcing (i.e. tide, wind, liquid and solid river flows) was applied on the three historic bathymetries (i.e. 1960, 1975 and 2010), considering no dredging activities and the same bed roughness distribution and initial sediment cover. Therefore, the only differences between the simulation experiments come from bathymetrical changes. Nonetheless, an additional experiment has been carried out in simulating the 2010 configuration, but considering dredging activities. This experiment is referred as ' 2010 -dredg'.

\section{Results and discussion}

The comparison of the numerical experiments is firstly discussed in terms of hydrodynamics (Section 4.1) and spatial distributions of salinity and SSC (Section 4.2). The analyses of ETM location and ETM mass are then discussed in Sections 4.3 and 4.4, respectively. In the following analyses and discussions, SSC refers as the suspended sediment concentration of the mud class only. The ETM location and mass estimates are based on the suspended mud dynamics as well, as it represents the foremost source of sediment in the water column.

This study is not a retrospective analysis of the years 1960, 1975 and 2010, as the meteorological and hydrological forcing are not representative of the 1960 and 1975 periods. Consequently, the objective is here to discuss the influence of different morphologies, mainly characterized by the estuary deepening and narrowing, on the suspended sediment dynamics. 


\subsection{Hydrodynamics}

\subsubsection{Tidal amplification}

From 1960 to 2010, the channel deepening and estuary narrowing did not change the water levels at the mouth (kp 370, Fig. 3c), but it clearly induced a tidal amplification along the estuary (Fig. 3a and b). The maximum tidal range particularly increased from Honfleur ( $\mathrm{kp} \mathrm{355)}$ to Tancarville (kp 338), with an amplification around $+0.5 \mathrm{~m}$ from 1960 to 1975 and $+1 \mathrm{~m}$ from 1960 to 2010 (Fig. 4a). Such results are in line with observations in other estuaries that also experienced significant channel deepening, as the Elbe, the Ems, the Scheldt and the Loire estuaries (Winterwerp et al. 2013). It is explained by the larger water depth that reduces the tidal dissipation and enables the tide to penetrate deeper up-estuary (van Maren et al. 2015). Note that the deepening concerns the lower estuary (Fig. 2), but also upstream up to Rouen harbour, which is $66 \mathrm{~km}$ upstream from Caudebec-en-Caux (Fig. $1)$.

\subsubsection{Tidal asymmetries}

As it propagates up-estuary, the tide is distorted and becomes more and more asymmetric. Different proxies can be used to characterize the tidal asymmetry (e.g. Friedrichs 2010; Van Maren and Winterwerp 2013). However, Nidzieko (2010) suggested that quantifying tidal asymmetry via skewness (i.e. third order moment about zero $\gamma_{0}$ of the velocity and/or water level time derivative) should be preferred over traditional metrics in estuaries with mixed tides. Following Nidzieko and Ralston (2012), it reads:

$\gamma_{0}=\frac{\mu^{3}}{\mu_{2}^{3 / 2}}$,

where the $m$-th moment about zero is defined as

$\mu_{m}=\frac{1}{N-1} \sum_{i=1}^{N}\left(n_{i}\right)^{m}$

and $N$ is the number of samples $n_{i}$. This is similar to skewness, which is typically defined as the normalized third moment about the mean. In this study, we use this method to quantify:

(i) the ebb/flood tidal current asymmetry $\gamma_{0}\left(U_{b o t}\right)$, referred as the 'velocity skew'. It is based on the along-estuary bottom velocity $U_{b o t}$ and quantified by substituting $n=U_{b o t}$;

(ii) the tidal duration asymmetry in the rise and fall of water level $\gamma_{0}\left(\zeta_{t}\right)$, referred as the duration asymmetry'. It is quantified by substituting the time derivative $n=\zeta_{t}=\partial \zeta / \partial t$.

For velocity, the tide is ebb dominant for $\gamma_{0}\left(U_{b o t}\right)<0$ and flood dominant for $\gamma_{0}\left(U_{b o t}\right)>0$; the duration of falling water is shorter than rising water for $\gamma_{0}\left(\zeta_{t}\right)<0$ and longer for $\gamma_{0}\left(\zeta_{t}\right)>0$.

These parameters were computed as the median over a neap-spring tidal period during low river flow in order to analyse their spatial distribution in the lower estuary between the two contrasted configurations of 1960 and 2010 (Fig. 5c-f). The spatial distributions of the maximum bottom current velocity were quantified as well (Fig. 5a-b). Despite the substantial evolution of the estuary mouth between 1960 and 2010, it is interesting to note that the magnitude of the maximum bottom current velocity remains similar (up to $2 \mathrm{~m} / \mathrm{s}$; Fig. 4b). Nevertheless, there are two main channels in 1960 and only one in 2010. It results in different pictures for the velocity skew distribution (Fig. 4c and Fig. 5c-d). The channelization observed in 2010 enhances the ebb dominance $\left(\gamma_{0}\left(U_{b o t}\right)<\right.$ 
0 ), as it was expected from the engineering works realized in the 60's (i.e. deepening and narrowing) to favour the sediment flushing out. Hence, following Lanzoni and Seminara (1998) conclusions, the main channel of the Seine Estuary that turned out to be fully ebb dominated in 2010 would be characterized as a weakly dissipative estuary.

In the lower estuary, the duration of the falling water is always longer that the rising water (Fig. 5e-f). However, such a typical asymmetry is mainly higher in 1960 than in 2010, which is clearly readable in Fig. 4d in following the estuary thalweg transect. Hence, while the Seine Estuary deepening and narrowing does not significantly change the maximum current velocity (Fig. 4b) in the main channel, it slightly decreases the velocity skew (Fig. 4c) and substantially decreases the tidal duration asymmetry (Fig. 4d). Such a decrease may be linked to less difference between tide celerity at high and low water, as water depth differences are reduced, or due to nonlinear amplification resulting from the estuary narrowing (Lanzoni and Seminara 1998). Winterwerp (2011) observed that a decrease in tidal asymmetry is generally expected from channel deepening, even if it is not clear what type of asymmetry they discussed (i.e. velocity skew or tidal duration). van Maren et al. (2015) quantified the tidal asymmetry via the phase lag in the velocity $\theta_{u}$ (and water level $\theta_{\zeta}$ ) of the $\mathrm{M}_{2}$ and $\mathrm{M}_{4}$ tidal components, with $\theta_{u}$ characterizing differences between peak ebb and flood flow velocities and $\theta_{\zeta}$ characterizing differences in ebb and flood durations. In the context of the Ems Estuary deepening from 1945 to 2005, they were surprised to observe that the computed asymmetry in $\theta_{u}$ and $\theta_{\zeta}$ changed little over time.

\subsubsection{Deepening effects versus narrowing effects}

It is complicated to differentiate the effects of narrowing and deepening on estuarine circulation, as both morphological changes were combined in this study. However, a deeper analysis of the Fig. 4 can provide some insights. From 1960 to 1975, the main channel deepened all along the lower estuary (pk 320-360, Fig. 4e) and narrowed due to the diking (Fig. 2). From 1975 to 2010, the main channel deepened in the outer part (pk 345-360, Fig. 4e), but it did not substantially narrow from pk 320 to 360 (Fig. 2). The tidal range increased along the lower estuary from 1960 to 1975 (compare dashed red and dash-dotted green lines in Fig. 4a); however from 1975 to 2010, it significantly increased in the outer part only (compare dash-dotted green and solid blue lines in Fig. 4a), where substantial deepening was observed. Contrastingly, the tidal velocity skew and tidal duration asymmetry decreased from 1960 to 1975 when the channel was considerably narrowed (compare dashed red and dash-dotted green lines in Fig. 4c and d), as it was expected from engineering works (i.e. diking) carried out in order to enhance ebb tidal currents and sediment flushing out. From 1975 to 2010, in spite of the channel deepening in the outer part, the tidal duration asymmetry did not decrease (compare dash-dotted green and solid blue lines in Fig. 4d), probably due to the limited changes in channel width.

Therefore, the tidal amplification seems to mainly respond to channel deepening, whereas the decrease in tidal velocity skew and tidal duration asymmetry seems to mainly respond to estuary narrowing. This is in agreement with previous studies, as van Maren et al. (2015) who observed little changes in tidal duration asymmetries in the Ems River, despite the channel deepening and the consequent tidal amplification, perhaps because the Ems River width did not change significantly. It is also in agreement with Lanzoni and Seminara (1998) who observed that the estuary narrowing strongly affect nonlinear phenomenon, and thus, tidal asymmetries. 


\subsection{Salinity and SPM spatial distributions}

As SSC is strongly related to salinity gradients in estuaries, the following analysis discusses simultaneously salinity and mud distributions in terms of two-dimensional (2D) views (Section 4.2.1) and one-dimensional (1D) alongestuary transects (Section 4.2.2).

\subsubsection{D distributions for contrasted hydrological periods}

In Fig. 6, the depth-averaged salinity has been computed as the median over a neap-spring tidal period during low river flow $\left(Q_{\text {mean }}=340 \mathrm{~m}^{3} / \mathrm{s}\right.$, Fig. 6a and c) and high river flow $\left(Q_{\text {mean }}=1340 \mathrm{~m}^{3} / \mathrm{s}\right.$, Fig. $6 \mathrm{~b}$ and d $)$. It provides insights in the contrasted salinity distributions for the 1960 and 2010 configurations. In both configurations, the lower estuary is largely dominated by fresh water during high river flow, and salinity fronts translate up-estuary by approximately 5 to $10 \mathrm{~km}$ during low river flow. However, the cross-section distributions are very contrasted. It is mainly uniform in 1960 in spite of the two main channels at the mouth, whereas it is strongly irregular in 2010 due to the dikes at the mouth. Such a channelization enhances the residual circulation at the mouth, increasing the saline water intrusion along the northern and southern sides of the dikes. This results in a drastic increase in intertidal area salinity (up to $10 \mathrm{psu}$ ), as observed in the "Vasière Nord" mud flat (i.e. the northern intertidal area between $\mathrm{kp} 350$ and 360).

Similarly as Fig. 6, the 2D distribution of the depth-averaged SSC is illustrated in Fig. 7 for low and high river flow. As expected in both 1960 and 2010 configurations, the maximum SSC zone, which is characteristic of the ETM area, is located more upstream during low river flow than during high river flow (e.g. Avoine et al. 1981). In addition, the median SPM seems to be less concentrated during high river flow. In contrast to the 1960 salinity distribution, the two main channels at the mouth are easily distinguishable from the 1960 SPM distribution. This is typical of the tidal-current induced sediment resuspension that is significantly higher in deeper channels, in agreement with the 2D distribution of maximum bottom current velocities (Fig. 5a-b). Moreover, deep channels represent privileged areas for fine sediment accumulation, as fluid mud layers (e.g. Becker et al. 2013). During low river flow, the SSC is observed to be distributed more upstream in 2010 than in 1960; however, it is not clearly readable during high river flow. Therefore, it motivates the need to further investigate the SSC distribution along an estuary transect.

\subsubsection{Along-estuary transects}

The lower estuary transect is defined as a cross-section-averaged estuary segment from kp 360 (i.e. Balise A, Fig. 1a) to kp 310 (i.e. Caudebec-en-Caux, Fig. 1a). In order not to account for unrepresentative high SSC values induced by small-depth local resuspension in intertidal areas, the estuary transect solely considers mean water depths deeper than $5 \mathrm{~m}$. The salinity front is characterized by the 1-psu limit derived from the cross-sectionaveraged bottom salinity $\left(S_{b o t}\right)$, considering mean water depths deeper than $5 \mathrm{~m}$ as well. The salinity vertical gradient is computed as the difference between the cross-section-averaged bottom and surface salinities $\left(\Delta S=S_{b o t}-S_{\text {surf }}\right)$. 
The surface SSC temporal evolution (Fig. 8d-f) highlights the neap-spring phasing, extending and intensifying the mud distribution during spring tides (Fig. 8a-c), and the hydrological influence, as observed in Fig. 7. Such dynamics has been extensively discussed in the present-day configuration (Grasso et al. 2018). Here, the comparison between the three morphologies reveals an up-estuary translation of the SSC distribution between the 1960 configuration and the 1975-2010 configurations. This up-river migration is associated with an increase in the SSC magnitude. Note that the SSC maximum is located slightly seaward of the salinity front location (purple line). The yearly-averaged SSC transects provide a more readable quantification of these changes (Fig. 9c). The 1975 and 2010 transects are very similar in terms of distribution and magnitude; nevertheless, the lowermost limit of the SSC distribution is simulated around $3 \mathrm{~km}$ up-river in 2010 than in 1975. Remarkably, taking into account dredging activities in the 2010 configuration hardly changes the SSC distribution in the lower estuary (dashed cyan line, Fig. 9c). This point is further addressed in Section 4.4. Contrastingly, the 1960 SSC transect is clearly less intense than in 2010 (-20\% in maximum surface SSC) and it is shifted seaward by approximately $10 \mathrm{~km}$.

The up-river migration of the SSC distribution between 1960 and 2010 is associated with an up-river migration of the salinity front by approximately $4 \mathrm{~km}$ (Fig. 9a). More remarkable, the salinity vertical gradient substantially increases from 1960 to 2010 configurations (Fig. 8g-i). In yearly-averaged, $\Delta S$ increases by $50 \%$ to more than 100\% between Fatouville (kp 350) and Tancarville (kp 338), reaching up to +2 psu near Fatouville (Fig. 9b). These observations directly result from the channel deepening that enhances the gravitational circulation, increasing the up-river salinity intrusion (e.g. Talke et al. 2009; Donker and de Swart 2013).

According to Winterwerp (2011)'s phasing on the estuarine response to a channel deepening, the SSC increase in the Seine Estuary from 1960 to 2010 would correspond to the first phase characterized by an increase in the up-river transport by gravitational circulation and a decrease in river-induced flushing. The second phase, related to the increase of internal tidal asymmetry because of pronounced interactions between the sediment load and the turbulence vertical mixing, cannot be investigated in this study as the sediment-induced turbulence damping is not taken into account in this model. However, the Seine Estuary SSC is not very high and little fluid mud is observed. Therefore, the turbulence vertical mixing is mainly driven by the salinity gradients, which are taken into account in the turbulent closure, rather than the sediment-induced turbulence damping. Moreover, van Maren et al. (2015) observed in their simulations that the vertical mixing asymmetry limitedly influences the modelled up-estuary transport. Besides, given the same bed roughness distribution in the three configurations, the SSC increase is not related to a hydraulic drag reduction effect (Winterwerp and Wang 2013).

The SSC distribution and ETM dynamics is largely driven by the gravitational circulation mechanism, induced by salinity stratification, and the tidal pumping mechanism, induced by tidal asymmetry (e.g. Scully and Friedrichs 2007). As the result of the estuary deepening and narrowing, the stratification is observed to increase and can potentially strengthen the gravitational circulation mechanism. Moreover, the tidal asymmetry in current velocity (velocity skew) remains fairly constant, but the tidal range increases. According to van Maren et al. (2015), the increasing tidal amplitude enhances the difference between the total sediment flux transported during flood and ebb flows, resulting in a larger up-estuary tidal transport. Hence, the increasing tidal range potentially strengthens the tidal pumping mechanism as well. The following Section 4.3 aims at investigating the relative influence of both mechanisms on the ETM location dynamics. 


\subsubsection{Method for estimating the ETM and salinity front locations}

The analysis of the ETM location, and the salinity front location as well, is based on the method proposed by Grasso et al. (2018). It consists in detrending the along-estuary location from the river flow variability in order to analyse the variations with regard to the tidal range changes. The ETM location is computed at high frequency (once per 15 minutes) as the median of the cross-section-averaged mud SSC transects (kp 320-370, $h>5 \mathrm{~m}$ ). In order to remove the semidiurnal ETM variability, the upper-tidal ETM location $x_{E T M}$ is defined as the uppermost ETM location from low to low tide. Therefore, it represents the maximum upriver ETM intrusion. Similarly, the tide-averaged salinity front location $x_{\text {Salinity }}$ is defined as the median (again of the high-frequency output from low to low tide) of the 1 psu location at $1 \mathrm{~m}$ above the bed, representing the near-bottom salinity gradient between the fresh river flow and the saline water.

$x_{E T M}$ and $x_{\text {Salinity }}$ are plotted versus the river flow (Fig. 10a, d and g), illustrating their strong correlation, and polynomial regression laws are derived (dashed lines) to extract the trends associated with $Q$, as $x_{Q, E T M, p}$ and $x_{Q, \text { Salinity, } p}$. Then, the variations associated with the tidal range read:

$\left\{\begin{array}{c}\Delta x_{E T M}=x_{E T M}-x_{Q, E T M, p} \\ \Delta x_{\text {Salinity }}=x_{\text {Salinity }}-x_{Q, \text { Salinity }, p}\end{array}\right.$.

Grasso et al. (2018) put in light the hysteresis responses of $\Delta x_{E T M}$ and $\Delta x_{\text {Salinity }}$ to the neap-to-spring phasing, associated with the time for stratification and tidal pumping mechanisms to develop. This phasing is quantified via the tidal range changes $(d T R)$, computed at a given tide $t$ as:

$d T R_{t}=\frac{T R_{t+1}-T R_{t-1}}{2}$

where $d T R>0$ defines a neap-to-spring period (increasing tidal range) and $d T R<0$ defines a spring-to-neap period (decreasing tidal range).

Note that Grasso et al. (2018) based their analysis on the bottom salinity front defined as 5 psu and the ETM location defined as the median location per semidiurnal tidal cycle.

\subsubsection{River-flow-detrended analysis}

The influence of river flow on salinity front and ETM locations is clearly illustrated in Fig. 10a, $d$ and $g$ for the three configurations, with seaward translations during high river flow. Nonetheless, the salinity front location is more sensitive (i.e. larger extension) to the river flow changes in 1960 (kp 340-356) compared to 1975 (kp 343 353 ) and 2010 (kp 340-351). Such a behaviour is observed as well in Fig. 8 (purple lines) through the hydrological year. As observed in Fig. 8 and Fig. 9 from the SSC transects, the ETM extends further seaward in 1960 (kp $337-$ 341.5) than in 1975 (kp 335.5-339.3) and 2010 (kp 334.3-340.6).

The river-flow-detrended variations of the salinity front $\Delta x_{\text {Salinity }}$ reveal contrasted behaviour between the different configurations (Fig. 10b, e and h). Grasso et al. (2018) discussed intensively the present-day configuration, based on the 2014-2015 hydro-meteorological forcing. A similar pattern is here observed (Fig. 10h), characterized by a substantial up-estuary migration during neap tide $(T R<5 \mathrm{~m})$. It is explained by the effect of the stratification stronger for low $T R$, enhancing the gravitational circulation and thus the up-river bottom salinity 
intrusion (Grasso et al. 2018). In addition, a moderate up-river migration is observed during spring tide (TR $>7 \mathrm{~m})$. Such a pattern can be explained by the water volume oscillating in the lower estuary (i.e. tidal prism) being larger during spring tide, pushing up-river the salinity front location (Guézennec 1998; Le Hir and Silva Jacinto 2007). The pattern in the 1960 configuration is strikingly different, as no up-estuary migration is observed during neap tide (Fig. 10b); the salinity front migrates up-estuary as the tidal range increases, probably resulting from the water volume increase mentioned previously. It implies that the stratification mechanism is hardly present in the 1960 configuration. The 1975 configuration represents an intermediate behaviour between the 1960 and 2010 patterns.

Another remarkable pattern concerns the hysteresis between the neap-to-spring (increasing $T R$ ) and spring-to-neap phasing (decreasing TR) phasing. In 2010 (Fig. 10h), for a given TR between 3 and $6 \mathrm{~m}$, the salinity front is located further downstream for spring-to-neap tides ( $d T R<0$, blue) than for neap-to-spring tides $(d T R>0$, red). Grasso et al. (2018) explained this difference by the delay for stratification to fully develop. In other words, during spring tide the water column is mainly mixed and homogenous, but with decreasing $T R$ (i.e. spring-to-neap phasing, blue) the stratification slowly develops until it reaches its maximum at neap tide, associated with an upward migration of the bottom salinity front (Burchard and Hetland 2010; Geyer and MacCready 2014). Such a type of hysteresis is not observed in the 1960 configuration; it seems to confirm that the gravitational circulation induced by stratification is not significantly effective in 1960. These results are in agreement with the increase of stratification from 1960 to 2010 configurations, as observed in Fig. 8 and Fig. 9. For the 1975 configuration, the influence of gravitational circulation looks to be stronger compared to the 1960 configuration (i.e. upper salinity intrusion during neap tide and higher neap-spring phasing hysteresis), whereas the vertical stratification is about the same (Fig. 9b). It can be explained by a stronger horizontal gradient of salinity, in agreement with the upperestuary salinity distribution observed for 1975 compared to 1960 (Fig. 9a), that is known to contribute to the gravitational circulation as well as the vertical gradient (e.g. Dyer 1973; Dronkers 1986; Geyer 1993).

The ETM location dynamics is similarly analysed as the salinity front dynamics (Fig. 10c, f and i). In 2010 (Fig. 10i), the ETM is translated up-estuary during neap tide, which is associated with the enhanced gravitational circulation, and during spring tide, which is associated with the enhanced tidal asymmetry and hence tidal pumping (e.g. Scully and Friedrichs 2007). The anti-clockwise hysteresis observed during neap tide $(T R<4.5 \mathrm{~m})$ corresponds to the time for the stratification to fully develop, and the clockwise hysteresis observed during spring tide $(T R>4.5 \mathrm{~m}$ ) corresponds to the time for the tidal pumping to fully develop (Grasso et al. 2018). In agreement with the salinity front dynamics, the ETM location in 1960 (Fig. 10c) does not migrate up-estuary during neap tide. Due to the reduction of substantial gravitational circulation, the ETM location dynamics is solely driven by the tidal pumping mechanism, increasing with the tidal range. In addition, the $T R$-induced variations are markedly larger in $1960([-5:+5] \mathrm{km})$ compared to $2010([-2:+2] \mathrm{km})$. Again, the 1975 configuration depicts an intermediate state between the 1960 tidal-pumping driven dynamics, and the 2010 configuration where the relative contributions of gravitational circulation and tidal pumping mechanisms are relatively balanced.

These results highlight that the influence of the gravitational circulation mechanism on salinity front and ETM dynamics increases in response to the Seine Estuary deepening and narrowing, as it has been discussed on other estuaries (e.g. Talke et al. 2009; Winterwerp 2011; Donker and de Swart 2013). Tidal amplification is observed as well (Fig. 4a); nevertheless, its influence on the ETM dynamics through an intensification of the tidal pumping mechanism is less obvious (Fig. 10c, $\mathrm{f}$ and i). Therefore, the morphological changes not only impact the 
ETM and salinity front locations, but they may modify the contributions of the driving mechanism as well. These changes result in a less extended, higher and upper-estuary SSC distribution (Fig. 9c).

Winterwerp and Wang (2013) observed that, in response to an estuary deepening, the enhanced flood flow dominance and reduced river's flushing capacity may lead to the creation of a second ETM related to the tidal pumping mechanism, located upstream of the formal ETM close to the salt wedge location. The potential occurrence of a second ETM in the Seine Estuary has been previously discussed (Allen et al. 1980; Brenon and Le Hir 1999). Nevertheless, it is not clearly observed in the 2010 configuration. It may be explained by the early state of the Seine Estuary within the transition from a normal to hyperturbid estuary (Winterwerp 2011). Nevertheless, Winterwerp and Wang (2013) inferred that with sufficient intertidal areas - i.e. at least $50 \%$ of the width of the flow carrying cross-section - tidal conditions would remain ebb-dominant, preventing the formation of second ETM conditions. In the Seine Estuary, intertidal areas in the lower estuary (i.e. from $\mathrm{kp}=320$ to 370 ) decreased by $50 \%$ from the 1960 and 1975 states to the 2010 state $\left(30.6,31.3\right.$ and $20.4 \mathrm{~km}^{2}$ in 1960,1975 and 2010, respectively). They represented approximately 19 and 20\% of the lower estuary in 1960 and 1975 , respectively, and only $14 \%$ in 2010 . Even reduced, these intertidal flats can accommodate large amounts of fine sediments, preventing their accumulation in the water column.

\subsection{Analysis of the ETM mass}

In order to quantify the ETM mass in the three configurations, the suspended mud concentration has been integrated over the entire lower estuary, extending from the black dashed line at the mouth in Fig. 7 (i.e. around kp 370) toward Caudebec-en-Caux upstream (kp 310). Intertidal areas are taken into account. The following analysis is based on the tide-maximum ETM mass, which is defined as the maximum of the high-frequency variations of the ETM mass from low to low tide. Simulations were run for two years; the results of the second (i.e. reference) year, following the first-year spin-up, were checked not to change substantially. As illustrated in Fig. 11, the ETM mass in the different configurations remains fairly stable over the two years, with a decrease of the yearly-averaged mass by less than $5 \%$ between the first and the second year.

The ETM mass is observed to be strongly modulated by the neap-spring tidal cycle and little by the hydrological cycle (e.g. Le Hir et al. 2001; Jalón-Rojas et al. 2015; Toublanc et al. 2016; Grasso et al. 2018). The non-linear relation between the ETM mass and the tidal range is highlighted in Fig. 12b. The maximum mass can reach around 300-330 kT during high spring tide $(T R=7.5 \mathrm{~m})$. This value slightly differs from the maximum mass simulated by Grasso et al. (2018) for the year 2014-2015 (i.e. around $250 \mathrm{kT}$ ), as the SSC integration domain is not the same. However, it is of the same order of magnitude than the ETM mass estimated by Avoine et al. (1981) from in situ measurements (i.e. around $300 \mathrm{kT}$ ).

Interestingly, the ETM mass hardly changes between the 1960 and 2010 configurations, whereas it slightly decreases in the 1975 configuration (Fig. 12b). For the large spring tides (i.e. $T R \sim 7.5 \mathrm{~m}$ ), the suspended mud mass reaches in average 332 kT, 298 kT and 333 kT in 1960, 1975 and 2010, respectively. Nonetheless, the mass distribution is reduced in 2010 (Fig. 12a), in agreement with the intensification of the SSC and the decrease of the longitudinal extension previously observed (Fig. 8, Fig. 9). These results imply that in the context of the Seine Estuary, the maximum ETM mass would not be significantly sensitive to the morphological changes experienced in the last 50 years, considering a given forcing and sufficient sediment bed availability. Further 
analyses will have to be done to investigate the sensitivity of the ETM mass to the hydrodynamic forcing and sediment availability.

The influence of dredging activities on suspended sediment dynamics has been investigated. Huge amounts of sediments are dredged by the model (around $5 \mathrm{MT} / \mathrm{yr}$ ), in fair agreement with the observations, and then damped out of the lower estuary domain (see damping locations in Fig. 1b). Despite these massive humaninduced sediment transfers, which each year represent more than 10 times the maximum ETM mass, hardly no changes are observed in terms of ETM mass (dashed cyan line in Fig. 12b). This is in agreement with the alongestuary SSC transects (Fig. 9c) that are similarly distributed for the 2010 configurations with and without dredging activities. Consequently, we infer that the ETM mass principally results from the hydrodynamic forcing (i.e. tidal energy), as long as sufficient fine sediment is available within the estuarine system.

\section{Conclusions}

A 3D numerical model of the Seine Estuary has been used to investigate the influence of the estuary morphological changes that occurred in the last 50 years (1960-2010) on the salinity and suspended sediment dynamics. The same realistic hydro-meteorological forcing was applied on three contrasted bathymetries (i.e. 1960, 1975 and 2010), characterizing the Seine Estuary deepening and narrowing. Simulations are discussed in terms of hydrodynamics (e.g. tidal amplification and asymmetry), hydrology (e.g. salinity front and stratification), and suspended mud dynamics (e.g. SSC, ETM location and mass).

The estuary deepening and narrowing induces a tidal amplification and a decrease of the tidal duration asymmetry in the main channel; however, the flood flow remains shorter and more intense than the ebb flow. The velocity skew (i.e. asymmetry in ebb/flood tidal velocities) slightly decreases in favour of an ebb-dominated channel. Contrastingly, the maximum bottom current velocities do not significantly change with morphological changes. Interestingly, the tidal amplification would mainly respond to channel deepening, whereas the decrease in tidal asymmetries (i.e. velocity skew and duration asymmetry) would mainly respond to estuary narrowing.

These changes induce the up-river migration of the bottom salinity front associated with the strengthening of the salinity vertical gradient (i.e. stratification). In addition, the salinity front location became less sensitive to river low changes. It results in intensifying the SSC distribution and reducing its extension, which is translated upestuary by approximately $10 \mathrm{~km}$. Based on a river-flow-detrended method used for analysing the salinity front and ETM locations, these behaviours are shown to arise from the enhanced gravitational circulation mechanism. Moreover, the 2010 configuration is characterized with a strong neap-to-spring phase hysteresis, corresponding to the time for stratification and tidal pumping to fully develop. Such a hysteresis is less noticeable in 1960, as the dynamics is mainly driven by the tidal pumping mechanism alone. Therefore, the morphological changes not only impact the ETM and salinity front locations, but they can modify the contributions of the driving mechanism as well.

The maximum mass of suspended mud does not significantly change with the estuary deepening and narrowing, but its distribution is less extended. Remarkably, dredging and damping activities have hardly any influence on the SSC distribution and ETM mass. Consequently, one can wonder whether the ETM mass principally results from the tidal forcing rather than the morphology and the bed thickness, as long as sufficient 
sediment availability remains within the system. It will be interesting to further investigate the influence of the hydrodynamic forcing on the ETM mass. In addition, an intercomparison study of different estuaries, based on a similar approach, would provide valuable insights in the estuarine suspended sediment responses to diverse changes in morphology, sediment distribution and hydro-meteorological forcing.

\section{Acknowledgements}

This study has been carried out in the framework of the ANPHYECO project funded by the scientific research programme Seine-Aval V. Nicolas Chini (ACRI-HE) and Jean-Philippe Lemoine (GIPSA, MESSCENE project) are warmly acknowledged for providing the 1960 and 1975 bathymetry configurations.

\section{References}

Allen GP, Salomon J, Bassoullet P, Du Penhoat Y, De Grandpre C (1980) Effects of tides on mixing and suspended sediment transport in macrotidal estuaries Sedimentary Geology 26:69-90

Amoudry LO, Ramirez-Mendoza R, Souza AJ, Brown JM (2014) Modelling-based assessment of suspended sediment dynamics in a hypertidal estuarine channel Ocean Dynamics 64:707-722 doi:10.1007/s10236-0140695-8

Avoine J, Allen G, Nichols M, Salomon J, Larsonneur C (1981) Suspended-sediment transport in the Seine estuary, France: effect of man-made modifications on estuary-shelf sedimentology Marine Geology 40:119-137

Becker M, Schrottke K, Bartholomä A, Ernstsen V, Winter C, Hebbeln D (2013) Formation and entrainment of fluid mud layers in troughs of subtidal dunes in an estuarine turbidity zone Journal of Geophysical Research: Oceans 118:2175-2187 doi:10.1002/jgrc.20153

Bi Q, Toorman EA (2015) Mixed-sediment transport modelling in Scheldt estuary with a physics-based bottom friction law Ocean Dynamics 65:555-587 doi:10.1007/s10236-015-0816-z

Brenon I, Le Hir P (1999) Modelling the turbidity maximum in the Seine estuary (France): identification of formation processes Estuarine, coastal and shelf science 49:525-544

Burchard H, Hetland RD (2010) Quantifying the contributions of tidal straining and gravitational circulation to residual circulation in periodically stratified tidal estuaries Journal of Physical Oceanography 40:1243-1262

Burchard H, Schuttelaars H, Ralston D (2018) Sediment Trapping in Estuaries Annual review of marine science 10:371-395

Chernetsky AS, Schuttelaars HM, Talke SA (2010) The effect of tidal asymmetry and temporal settling lag on sediment trapping in tidal estuaries Ocean Dynamics 60:1219-1241

Cugier P, Le Hir P (2002) Development of a 3D hydrodynamic model for coastal ecosystem modelling. Application to the plume of the Seine River (France) Estuarine, Coastal and Shelf Science 55:673-695

de Jonge VN, Schuttelaars HM, van Beusekom JE, Talke SA, de Swart HE (2014) The influence of channel deepening on estuarine turbidity levels and dynamics, as exemplified by the Ems estuary Estuarine, Coastal and Shelf Science 139:46-59

Deloffre J, Lafite R, Lesueur P, Lesourd S, Verney R, Guézennec L (2005) Sedimentary processes on an intertidal mudflat in the upper macrotidal Seine estuary, France Estuarine, Coastal and Shelf Science 64:710-720 doi:10.1016/j.ecss.2005.04.004

Deloffre J, Verney R, Lafite R, Lesueur P, Lesourd S, Cundy AB (2007) Sedimentation on intertidal mudflats in the lower part of macrotidal estuaries: Sedimentation rhythms and their preservation Marine Geology 241:1932 doi:10.1016/j.margeo.2007.02.011

Dickhudt PJ, Friedrichs CT, Schaffner LC, Sanford LP (2009) Spatial and temporal variation in cohesive sediment erodibility in the York River estuary, eastern USA: A biologically influenced equilibrium modified by seasonal deposition Marine Geology 267:128-140

Donker JJ, de Swart HE (2013) Effects of bottom slope, flocculation and hindered settling on the coupled dynamics of currents and suspended sediment in highly turbid estuaries, a simple model Ocean dynamics 63:311-327

Dronkers J (1986) Tide-Induced Residual Transport of Fine Sediment Physics of shallow estuaries and bays:228244

Dyer KR (1973) Estuaries: a physical introduction.

Friedrichs C, Armbrust B, De Swart H (1998) Hydrodynamics and equilibrium sediment dynamics of shallow, funnel-shaped tidal estuaries Physics of estuaries and coastal seas:315-327 
Friedrichs CT (2010) Barotropic tides in channelized estuaries Contemporary issues in estuarine physics:27-61

Geyer WR (1993) The importance of suppression of turbulence by stratification on the estuarine turbidity maximum Estuaries 16:113-125

Geyer WR, MacCready P (2014) The Estuarine Circulation. In: Davis SH, Moin P (eds) Annual Review of Fluid Mechanics, Vol 46, vol 46. Annual Review of Fluid Mechanics. Annual Reviews, Palo Alto, pp 175-197. doi:10.1146/annurev-fluid-010313-141302

Gibson R, England G, Hussey M (1967) The Theory of one-dimensional consolidation of saturated clays: 1 . finite non-Linear consildation of thin homogeneous layers Geotechnique 17:261-273

Glangeaud L (1938) Transport et sédimentation dans l'estuaire et à l'embouchure de la Gironde. Caractères pétrographiques des formations fluviatiles, saumâtres, littorales et néritiques Bulletin de la Societe Geologique de France, Paris 7:599-630

Grasso F, Le Hir P, Bassoullet P (2015) Numerical modelling of mixed-sediment consolidation Ocean Dynamics 65:607-616

Grasso F et al. (2018) Suspended Sediment Dynamics in the Macrotidal Seine Estuary (France): 1. Numerical Modeling of Turbidity Maximum Dynamics Journal of Geophysical Research: Oceans 123:558-577 doi:10.1002/2017JC013185

Guézennec L (1998) Hydrodynamique et transport en suspension du matériel particulaire fin dans la zone fluviale d'un estuaire macrotidal: l'exemple de l'estuaire de la Seine (France). Rouen

Jalón-Rojas I, Schmidt S, Sottolichio A (2015) Turbidity in the fluvial Gironde Estuary (southwest France) based on 10-year continuous monitoring: sensitivity to hydrological conditions Hydrology and Earth System Sciences 19:2805-2819 doi:10.5194/hess-19-2805-2015

Jalón-Rojas I, Schmidt S, Sottolichio A, Bertier C (2016) Tracking the turbidity maximum zone in the Loire Estuary (France) based on a long-term, high-resolution and high-frequency monitoring network Continental Shelf Research 117:1-11 doi:10.1016/j.csr.2016.01.017

Jay D, Musiak J (1994) Particle trapping in estuarine turbidity maxima Journal of Geophysical Research 99:446420

Landemaine V (2016) Erosion des sols et transferts sédimentaires sur les bassins versants de l'Ouest du Bassin de Paris: analyse, quantification et modélisation à l'échelle pluriannelle

Lanzoni S, Seminara G (1998) On tide propagation in convergent estuaries Journal of Geophysical Research: Oceans 103:30793-30812

Lazure P, Dumas F (2008) An external-internal mode coupling for a 3D hydrodynamical model for applications at regional scale (MARS) Advances in Water Resources 31:233-250

Le Hir P, Cayocca F, Waeles B (2011) Dynamics of sand and mud mixtures: A multiprocess-based modelling strategy Continental Shelf Research 31:S135-S149 doi:10.1016/j.csr.2010.12.009

Le Hir P et al. (2001) Fine sediment transport and accumulations at the mouth of the Seine estuary (France) Estuaries 24:950-963

Le Hir P, Silva Jacinto R (2007) Currents, waves and tides: water movements, vol Booklet N² of the Seine-Aval programme, Quae ed., 31p.

Le Hir P, Thouvenin B (1994) Mathematical modelling of cohesive sediment and particulate contaminants transport in the Loire Estuary OLSEN \& OLSEN, FREDENSBORG, DENMARK:71-78

Lesourd S, Lesueur P, Fisson C, Dauvin J-C (2015) Sediment evolution in the mouth of the Seine estuary (France): A long-term monitoring during the last 150years Comptes Rendus Geoscience

Marmin S, Dauvin JC, Lesueur P (2014) Collaborative approach for the management of harbour-dredged sediment in the Bay of Seine (France) Ocean \& Coastal Management 102:328-339 doi:10.1016/j.ocecoaman.2014.10.012

Mengual B, Hir P, Cayocca F, Garlan T (2017) Modelling Fine Sediment Dynamics: Towards a Common Erosion Law for Fine Sand, Mud and Mixtures Water 9:564 doi:10.3390/w9080564

Morris A, Mantoura R, Bale A, Howland R (1978) Very low salinity regions of estuaries: important sites for chemical and biological reactions Nature 274:678-680

Nichols FH, Cloern JE, Luoma SN, Peterson DH (1986) The modification of an estuary Science(Washington) 231:567-573

Nidzieko N, Ralston D (2012) Tidal asymmetry and velocity skew over tidal flats and shallow channels within a macrotidal river delta Journal of Geophysical Research: Oceans 117

Nidzieko NJ (2010) Tidal asymmetry in estuaries with mixed semidiurnal/diurnal tides Journal of Geophysical Research: Oceans 115

Partheniades E (1965) Erosion and deposition of cohesive soils Journal of the Hydraulics Division 91:105-139

Postma H (1961) Transport and accumulation of suspended matter in the Dutch Wadden Sea Netherlands Journal of Sea Research 1:148-190

Schulz E, Grasso F, Le Hir P, Verney R, Thouvenin B (2018) Suspended Sediment Dynamics in the Macrotidal Seine Estuary (France): 2. Numerical Modeling of Sediment Fluxes and Budgets Under Typical Hydrological 
and Meteorological Conditions Journal of Geophysical Research: Oceans 123:578-600 doi:10.1002/2016JC012638

Scully ME, Friedrichs CT (2007) Sediment pumping by tidal asymmetry in a partially mixed estuary Journal of Geophysical Research: Oceans 112

Sommerfield CK, Wong KC (2011) Mechanisms of sediment flux and turbidity maintenance in the Delaware Estuary Journal of Geophysical Research-Oceans 116 doi:Artn C01005

$10.1029 / 2010 j \mathrm{j} 006462$

Sottolichio A, Le Hir P, Castaing P (2000) Modeling mechanisms for the stability of the turbidity maximum in the Gironde estuary, France Proceedings in Marine Science 3:373-386

Talke SA, de Swart HE, Schuttelaars H (2009) Feedback between residual circulations and sediment distribution in highly turbid estuaries: an analytical model Continental Shelf Research 29:119-135

Toublanc F, Brenon I, Coulombier T (2016) Formation and structure of the turbidity maximum in the macrotidal Charente estuary (France): Influence of fluvial and tidal forcing Estuarine, Coastal and Shelf Science 169:1 14 doi:10.1016/j.ecss.2015.11.019

Uncles R (2002) Estuarine physical processes research: some recent studies and progress Estuarine, Coastal and Shelf Science 55:829-856

Van Leussen W (1994) Estuarine macroflocs and their role in fine-grained sediment transport. Ministry of Transport, Public Works and Water Management, National Institute for Coastal and Marine Management (RIKZ),

Van Maren D, Winterwerp J (2013) The role of flow asymmetry and mud properties on tidal flat sedimentation Continental Shelf Research 60:S71-S84

van Maren DS, Winterwerp JC, Vroom J (2015) Fine sediment transport into the hyper-turbid lower Ems River: the role of channel deepening and sediment-induced drag reduction Ocean Dynamics 65:589-605 doi:10.1007/s10236-015-0821-2

Verney R, Deloffre J, Brun-Cottan JC, Lafite R (2007) The effect of wave-induced turbulence on intertidal mudflats: Impact of boat traffic and wind Continental Shelf Research 27:594-612 doi:10.1016/j.csr.2006.10.005

Winterwerp JC (2011) Fine sediment transport by tidal asymmetry in the high-concentrated Ems River: indications for a regime shift in response to channel deepening Ocean Dynamics 61:203-215

Winterwerp JC, Wang ZB (2013) Man-induced regime shifts in small estuaries-I: theory Ocean Dynamics 63:1279-1292

Winterwerp JC, Wang ZB, van Braeckel A, van Holland G, Kösters F (2013) Man-induced regime shifts in small estuaries-II: a comparison of rivers Ocean Dynamics 63:1293-1306 


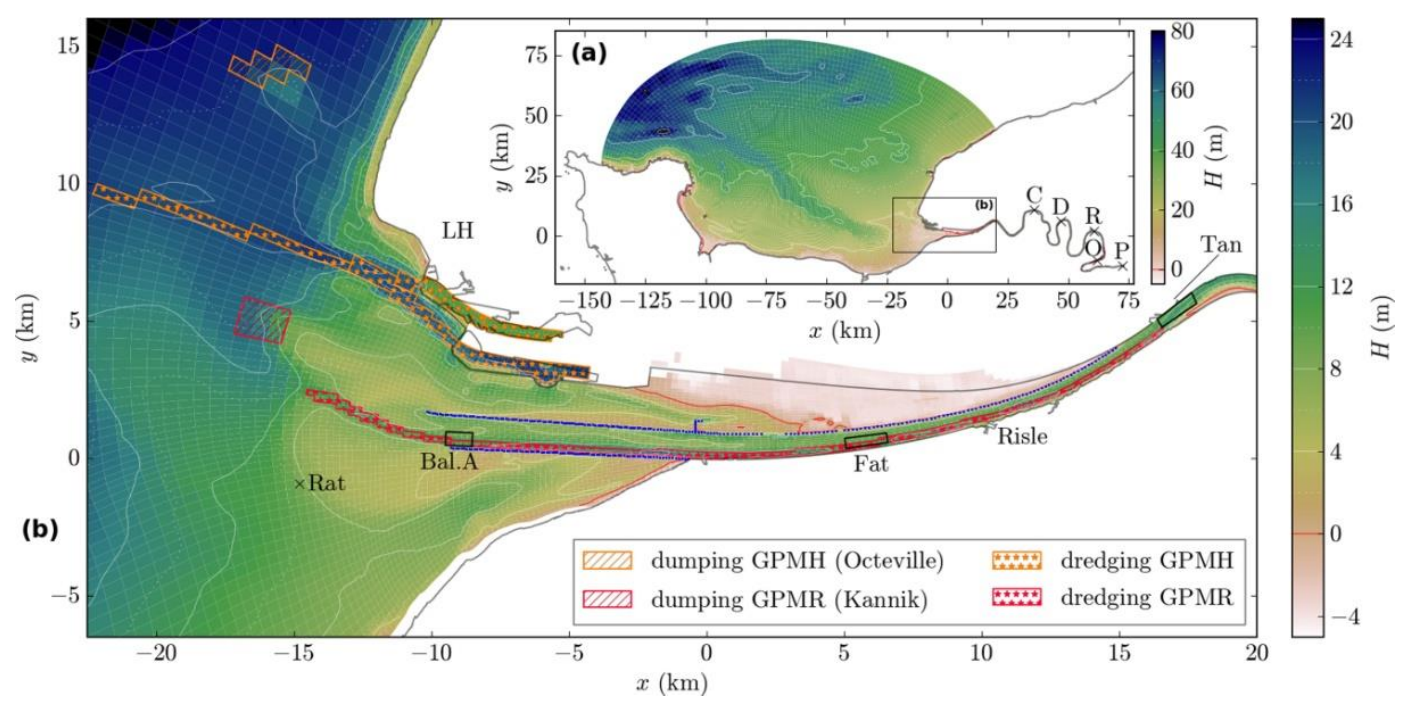

Fig. 1 Bathymetry (mean sea level chart datum) of the Seine Estuary (NW France) numerical model: (a) extending from the Bay of Seine to the weir of Poses ' $\mathrm{P}$ ' and (b) a zoom on the lower estuary. Dredging (stars) and dumping (hatching) areas for the GPMH (orange) and GPMR (red). Specific locations: Le Havre 'LH', Ratelets 'Rat', Caudebec-en-Caux ' $\mathrm{C}$ ', Duclair 'D', Rouen ' $\mathrm{R}$ ' and Oissel 'O'. The blue lines represent the dikes 


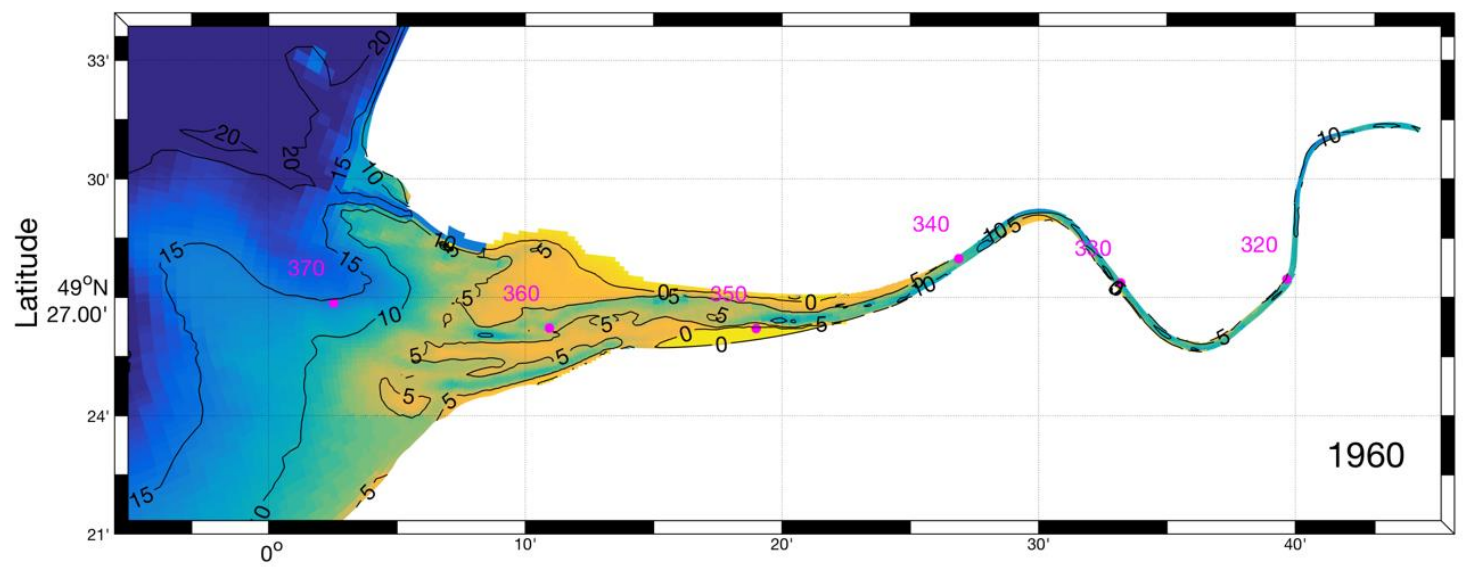

$\mathrm{h}(\mathrm{m})$
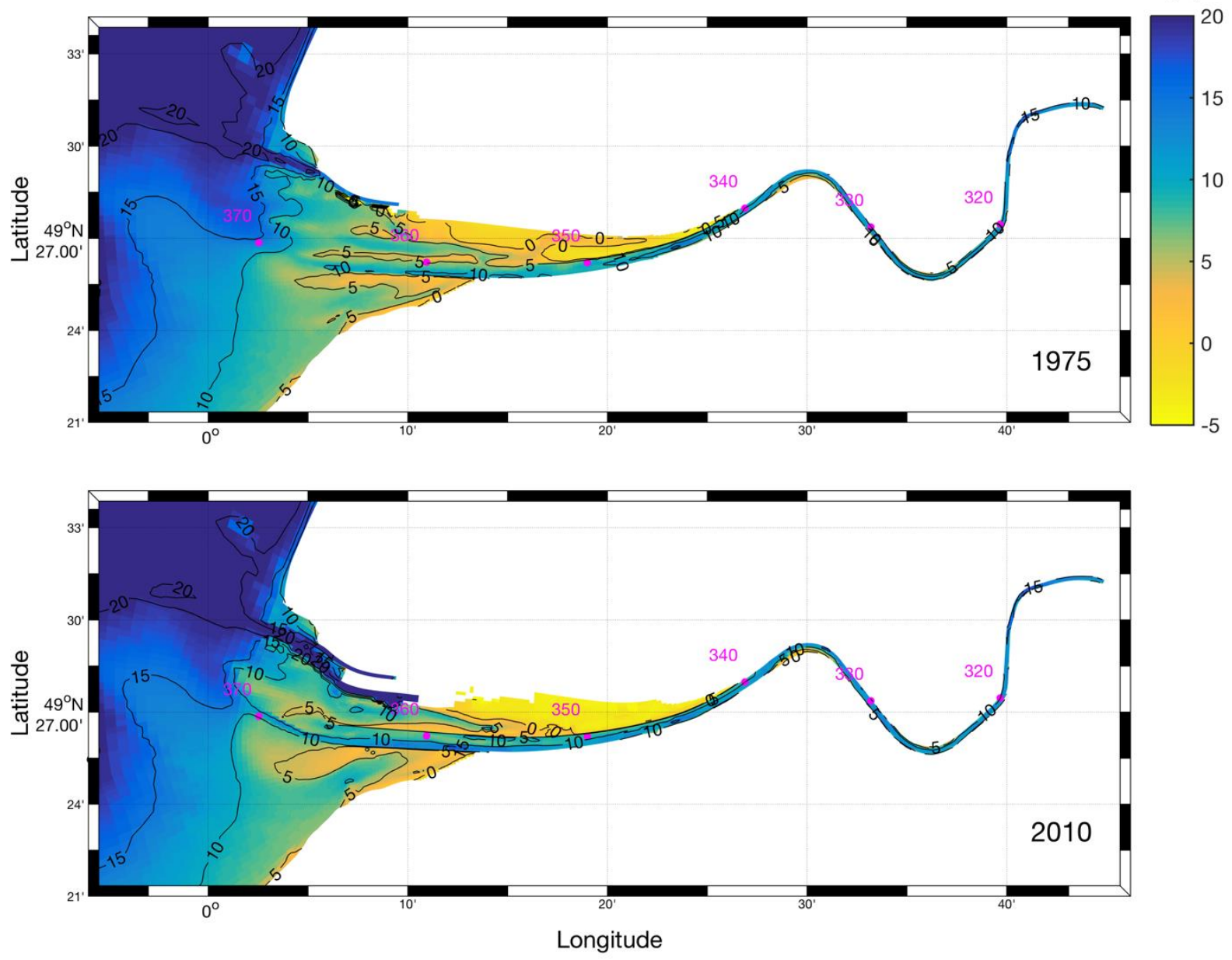

Fig. 2 Bathymetries (mean sea level chart datum) of the lower Seine Estuary in 1960 (top panel), 1975 (middle panel) and 2010 (bottom panel). The black contours represent 5-m isobaths and the purple dots represent kilometric point $(\mathrm{kp})$ locations along the estuary 

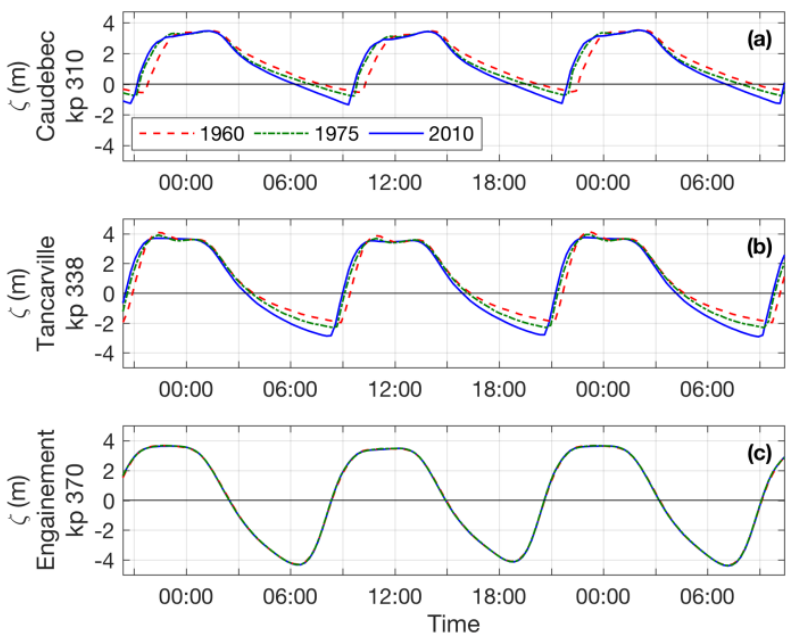

Fig. 3 Water surface elevations at (a) Caudebec-en-Caux, kp 310, (b) Tancarville, kp 338, and (c) Engainement, kp 370 (see locations in Fig. 1 and Fig. 2). Simulations for the 1960 (dashed red), 1975 (dash-dotted green) and 2010 (plain blue) configurations during a spring tidal period in low river flow

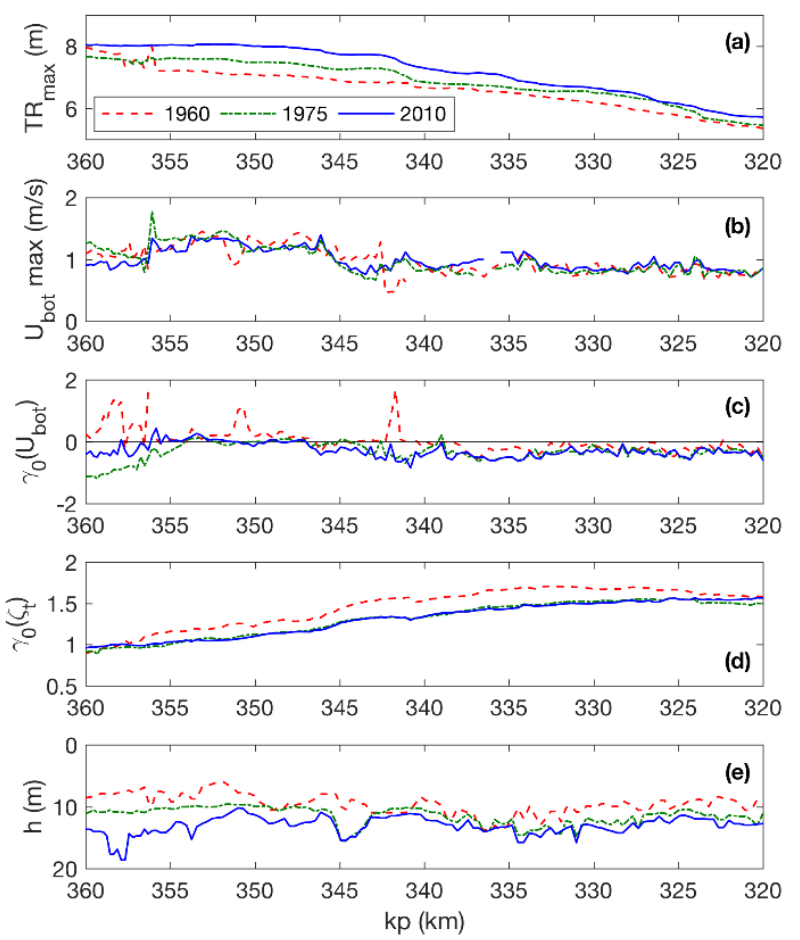

Fig. 4 Along-estuary hydrodynamic parameters for the 1960 (dashed red), 1975 (dash-dotted green) and 2010 (plain blue) configurations. (a) Maximum tidal range, (b) maximum bottom current velocity, expressed as the $99^{\text {th }}$ percentile, (c) tidal velocity skewness $\boldsymbol{\gamma}_{\mathbf{0}}\left(\boldsymbol{U}_{\boldsymbol{b} o t}\right)$, (d) tidal duration asymmetry $\boldsymbol{\gamma}_{\mathbf{0}}\left(\boldsymbol{\zeta}_{\boldsymbol{t}}\right)$ and (e) estuary thalweg in meters below mean sea level. Parameters computed along the estuary thalweg as the median over a neap-spring tidal period during low river flow 

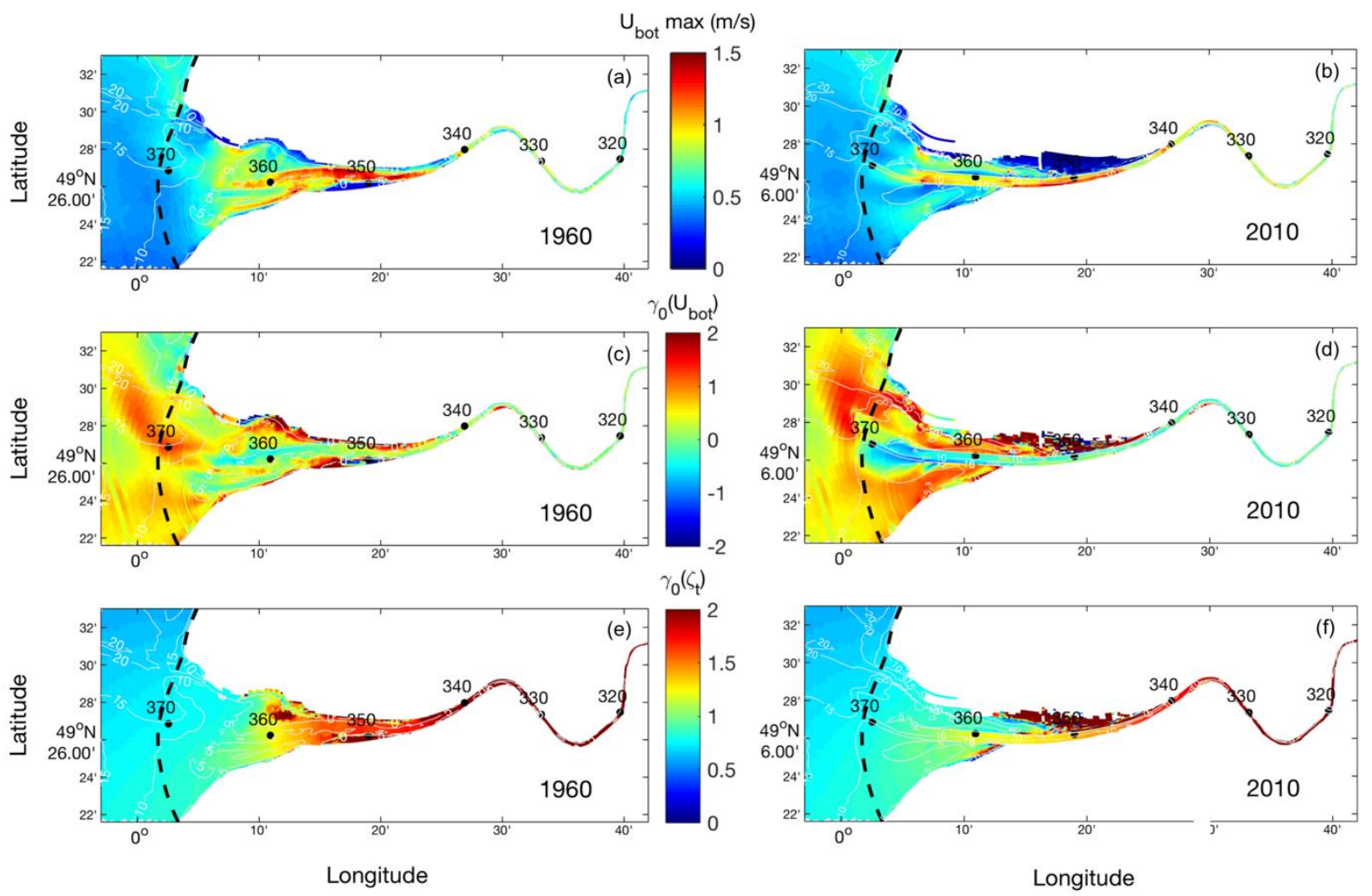

Fig. 5 Spatial distribution of hydrodynamic parameters in the 1960 (left panels) and 2010 (right panels) configurations. (a, b) Maximum bottom current velocity, expressed as the $99^{\text {th }}$ percentile, $(\mathrm{c}, \mathrm{d})$ tidal velocity skewness $\boldsymbol{\gamma}_{\mathbf{0}}\left(\boldsymbol{U}_{\boldsymbol{b o t}}\right)$, and (e, f) tidal duration asymmetry $\boldsymbol{\gamma}_{\mathbf{0}}\left(\boldsymbol{\zeta}_{t}\right)$. Parameters computed as the median over a neapspring tidal period during low river flow. The white contours represent 5-m isobaths, the black dots represent kp locations and the black dashed line represents the lower-most estuary limit used for SSC analyses
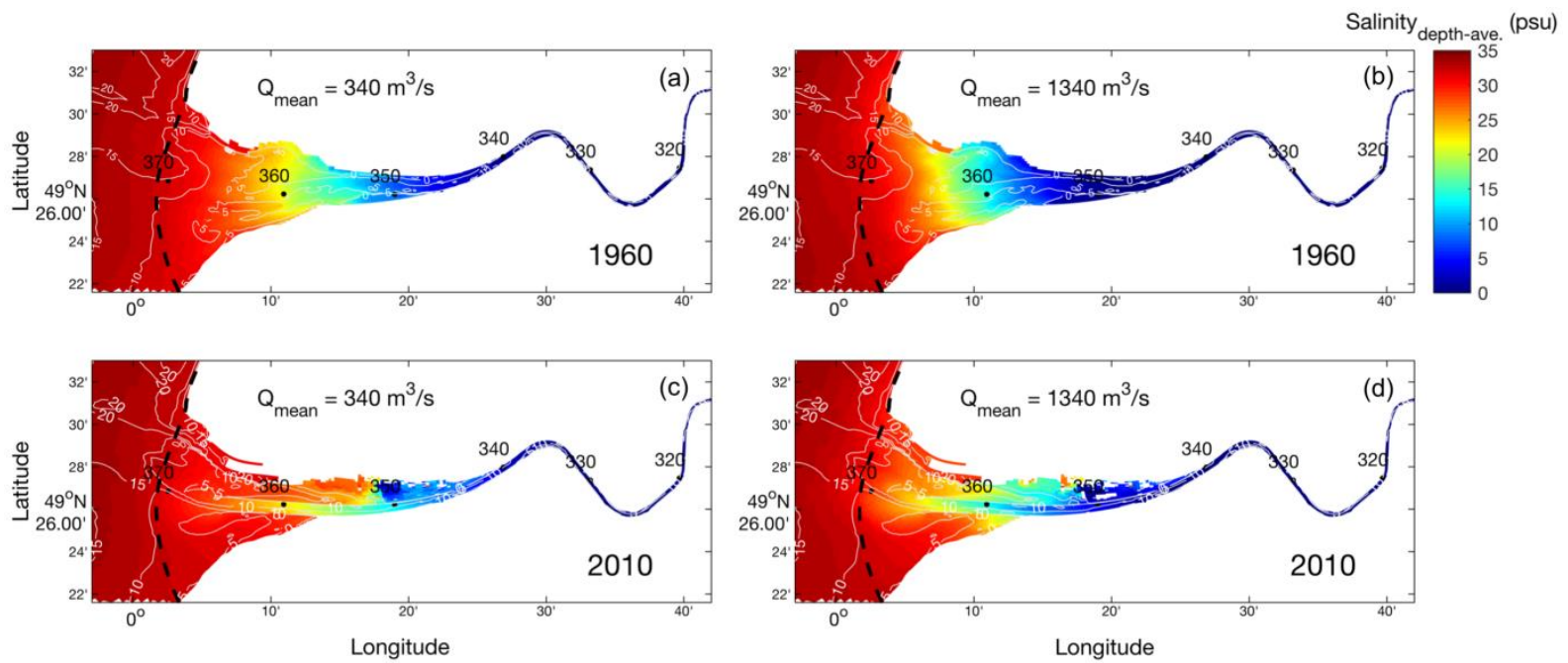

Fig. 6 Spatial distribution of depth-averaged salinity in the 1960 (top panels) and 2010 (bottom panels) configurations. Median values over a neap-spring tidal period during (a, c) low river flow $\left(Q_{\text {mean }}=340 \mathrm{~m}^{3} / \mathrm{s}\right)$ and $(\mathrm{b}, \mathrm{d})$ high river flow $\left(Q_{\text {mean }}=1340 \mathrm{~m}^{3} / \mathrm{s}\right)$. The white contours represent 5-m isobaths, the black dots represent $\mathrm{kp}$ locations and the black dashed line represents the lower-most estuary limit used for SSC analyses 

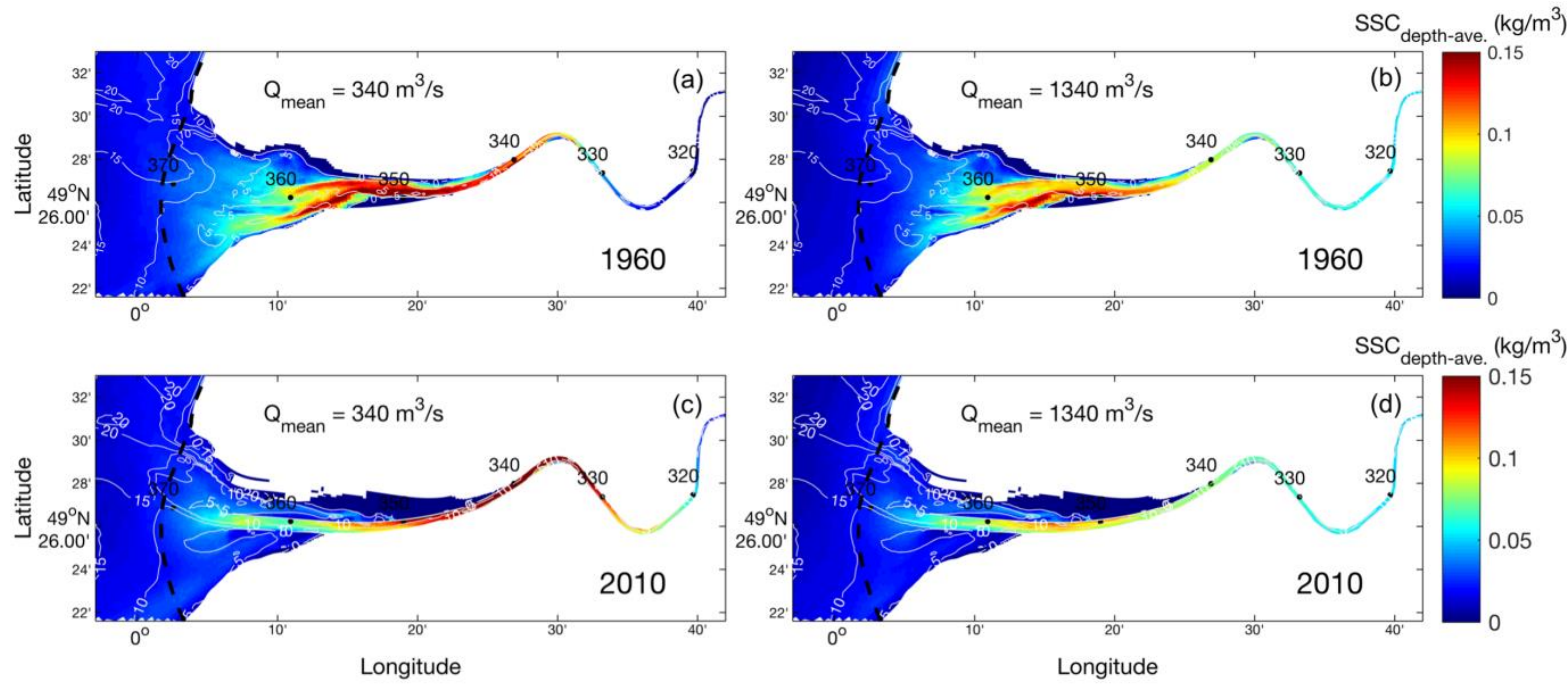

Fig. 7 Spatial distribution of depth-averaged mud SSC in the 1960 (top panels) and 2010 (bottom panels)

configurations. Median values over a neap-spring tidal period during (a, c) low river flow $\left(Q_{\text {mean }}=340 \mathrm{~m}^{3} / \mathrm{s}\right)$ and (b, d) high river flow $\left(Q_{\text {mean }}=1340 \mathrm{~m}^{3} / \mathrm{s}\right)$. The white contours represent 5-m isobaths, the black dots represent kp locations and the black dashed line represents the lower-most estuary limit used for SSC analyses
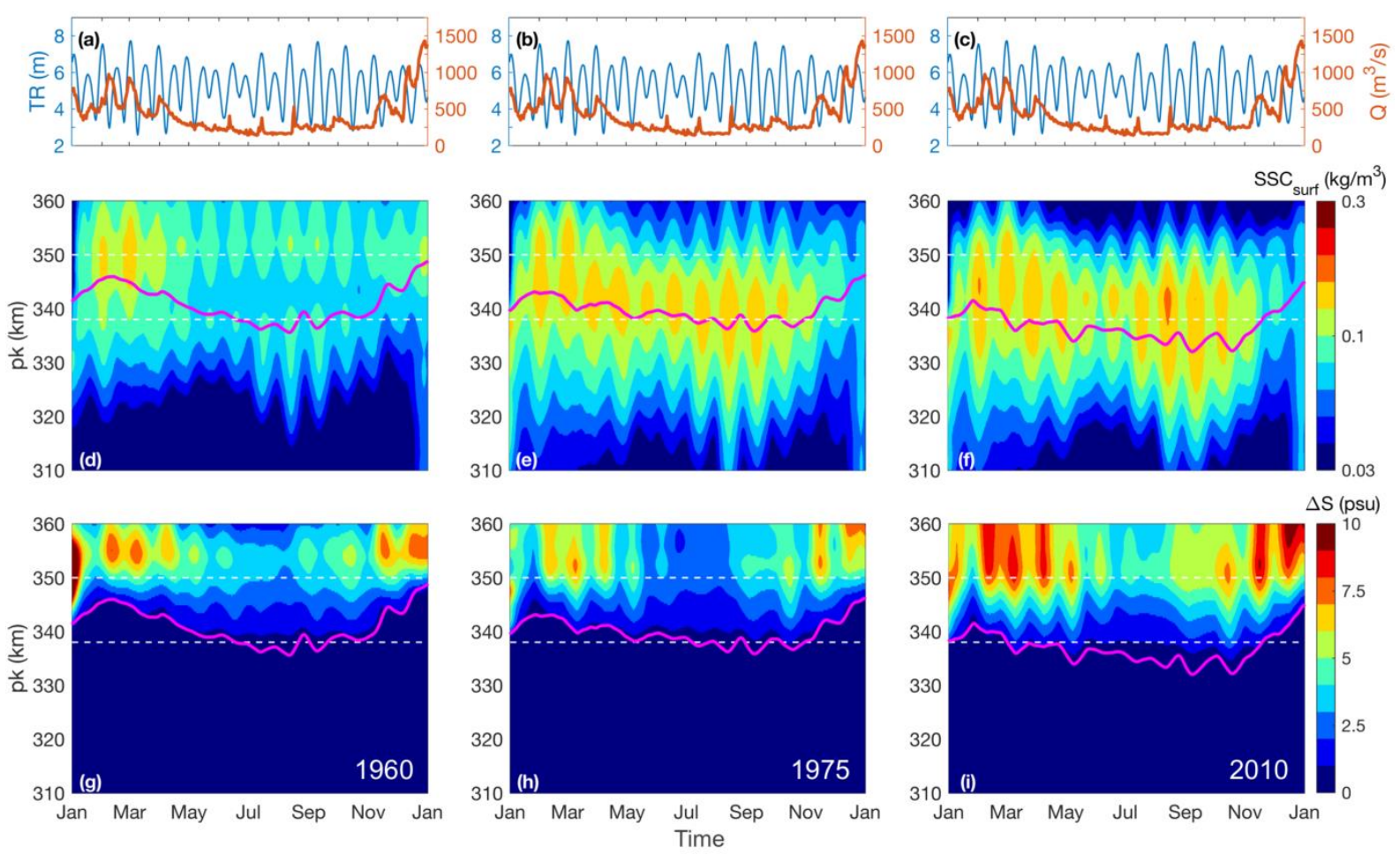

Fig. 8 Time evolution of along-estuary transects of (d-f) surface mud suspension $S S C_{\text {surf }}$ and (g-i) salinity vertical gradient $\Delta S$ for the (left panels) 1960, (centre panels) 1975 and (right panels) 2010 configurations. (a-c) Year 2010 realistic forcing, with tidal range TR (blue) and river flow $Q$ (orange), similarly applied to the three configurations. The purple lines in panels (d-i) represent the salinity front location, defined as the 1-psu bottom salinity limit. The horizontal white dashed lines represent Fatouville (kp 350) and Tancarville (kp 338) locations 

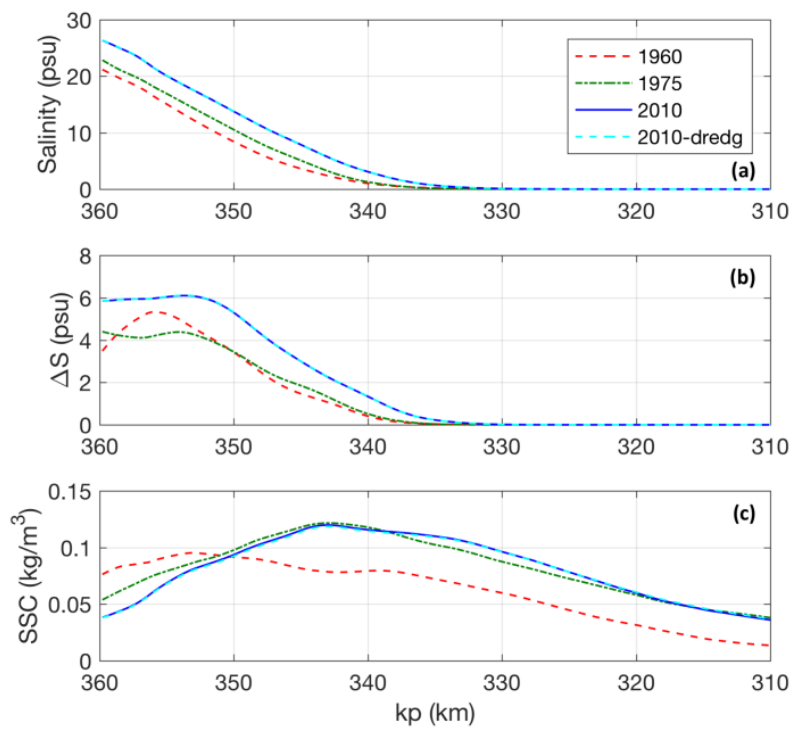

Fig. 9 Along-estuary transects of yearly-averaged (a) bottom salinity, (b) salinity vertical gradient $\Delta S$ and (c) surface mud suspension $S S C_{\text {surf }}$, for the 1960 (dashed red line), 1975 (dash-dotted green) and 2010 (plain blue) configurations. The 2010 configuration taking into account dredging activities (2010-dredg) is represented as well (dashed cyan)
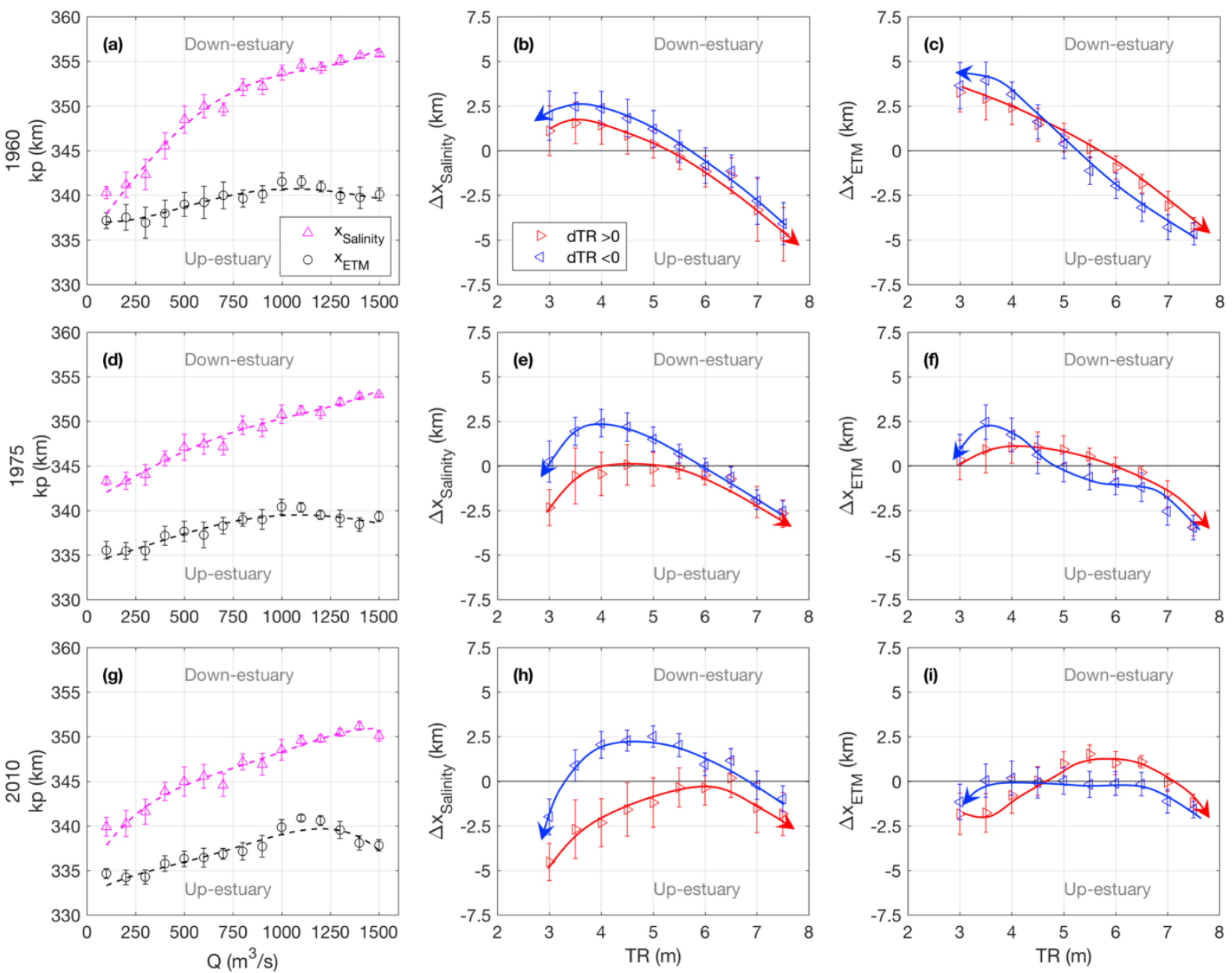

Fig. 10 (Left panels) Simulated ETM and salinity front locations, $x_{E T M}$ and $x_{\text {Salinity }}$, versus the Seine River flow $Q$. River-flow-detrended location variations (see Eq. (3)) of (centre panels) bottom salinity front $\Delta x_{\text {Salinity }}$ and (right 
panels) ETM $\Delta x_{E T M}$ versus tidal range $T R$ for neap-to-spring ( $d T R>0$, red rightward triangles) and spring-toneap ( $d T R<0$, blue leftward triangles) phasing. (a-c) 1960 configuration, (d-f) 1975 configuration and (g-i) 2010 configuration. In left panels, black and purple lines represent polynomial regression laws for $x_{E T M}$ and $x_{\text {Salinity }}$, respectively; symbols and vertical bars represent data average and standard deviation, respectively, associated with $Q$ ranges $\left(100 \mathrm{~m}^{3} / \mathrm{s}\right)$. In centre and right panels, triangles and vertical bars represent data average and standard deviation, respectively, associated with $T R$ ranges $(0.5 \mathrm{~m})$; arrows represent the schematic dynamics associated with neap-to-spring (red) and spring-to-neap (blue) phasing
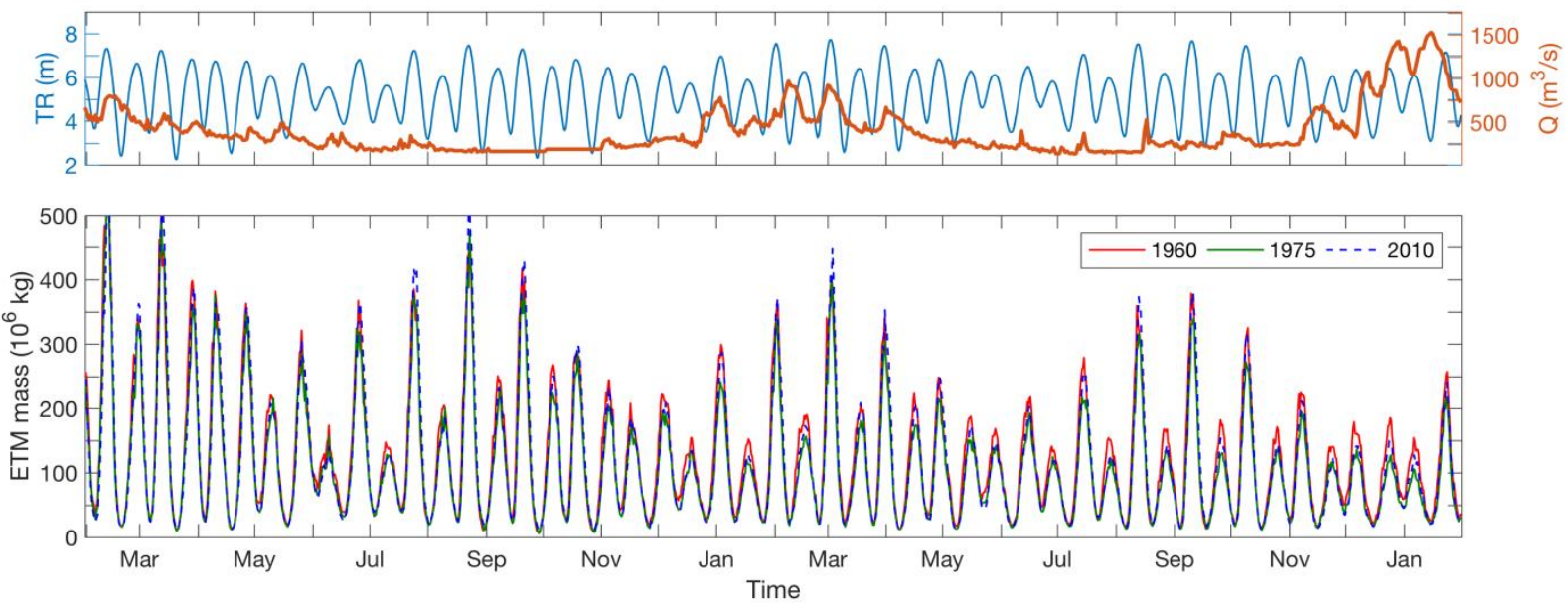

Fig. 11 (Bottom panel) Time evolution of tide-maximum ETM mass for the 1960 (plain red line) 1975 (plain green line) and 2010 (dashed blue line) configurations. (Top panel) Years 2009-2010 realistic forcing, with tidal range $T R$ (blue) and river flow $Q$ (orange), similarly applied to the three configurations
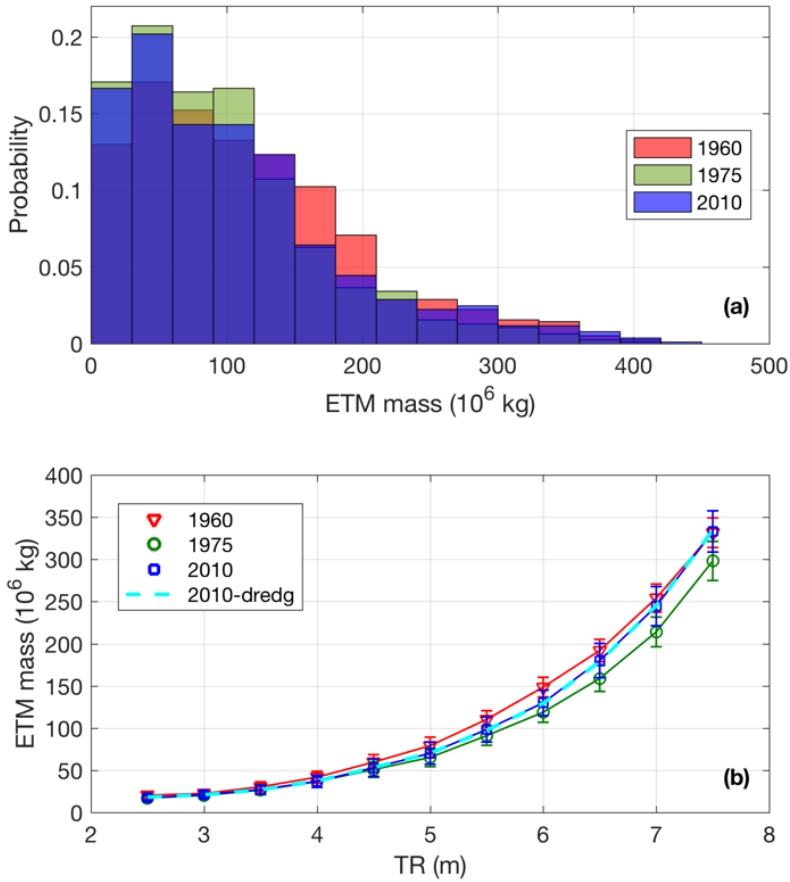
Fig. 12 (a) Tide-maximum ETM mass distribution and (b) tide-maximum ETM mass versus tidal range $T R$, for the 1960 (red triangles), 1975 (green circles) and 2010 (blue squares) configurations. The 2010 configuration taking into account dredging activities (2010-dredg) is represented in panel (b) as well (dashed cyan). In panel (b), symbols and vertical bars represent data average and standard deviation, respectively, associated with $T R$ ranges $(0.5 \mathrm{~m})$ 